\title{
Interpretation of Mass Spectra of Condensates From Urban Atmospheres
}

\author{
E. R. Weaver, ${ }^{1}$ E. E. Hughes, Shirley M. Gunther, Shuford Schuhmann, Nancy T. Redfearn \\ and Ralph Gorden, Jr.
}

\begin{abstract}
A method of interpreting the mass spectra of the very complex mixtures of substances that condense from an urban atmosphere at the temperature of liquid oxygen is described. The number of individual chemical compounds in such a mixture is greatly in excess of the number of masses recorded, and it is accordingly impossible to identify all the compounds present. However, the significant sources of pollutants are much less numerous, and if the products from each source are of substantially constant composition it is possible to obtain a representative pattern of each and to proceed thereafter to make a fairly good estimate of the character and amount of pollutants in terms of their sources. The greatest simplification is made by treating the gases associated with motor traffic as a unit.
\end{abstract}

\section{Introduction}

At an early stage in the study of air pollution in the Los Angeles area, it was proposed by Martin Shepherd [1] ${ }^{2}$ that condensible gases be collected from the atmosphere by cooling and filtering at the temperature of boiling oxygen and subsequently subjected to analysis by mass spectrometer. During 1949-51, approximately 50 samples were taken in the vicinity of Los Angeles by this method, all of which gave very complicated spectra whose interpretation was undertaken with only limited success [2, 3]. Subsequently, similar samples were taken in several cities under various circumstances. All of these have shown a basic similarity, which indicates that most of the polluting gases in each urban atmosphere are the same chemical substances in much the same proportions, and are of the general character of "products of combustion."

It is fairly obvious that in any city we may expect large volumes of products of combustion to enter the air from three sources: (1) From fuel used for heating buildings and producing power, (2) from automobiles, and (3) from waste disposal. In most cities the first is important only during cold weather and the third is intermittent or localized. The second is continuous and universal. It would be desirable and may yet be possible to find distinguishing characteristics between these three sources, but their principal differences appear to depend on the completeness of combustion of the fuel rather than on its type, whether coal, petroleum products, or wood and paper. When combustion is "complete," only carbon dioxide, water vapor, and a little sulfur dioxide, nitric oxide, and nitrogen dioxide, are added to the air, and oxygen, in negligible amount, is removed from it. When combustion is "incomplete," but as nearly complete as it can readily be made under the conditions of burning, carbon monoxide is the chief component of the "products of incomplete combustion," and hydrogen and various hydrocarbons are the most easily identified of the addi-

\footnotetext{
${ }^{1}$ Retired, present address: 6815 Connecticut Ave., Chevy Chase 15, Md.
}

2 Figures in brackets indicate the literature references at the end of this paper. tional products. As conditions are changed to make combustion less complete, products become more complex and more dependent on the character of the original fuel; but to the stage in which visible smoke appears, sufficient to attract attention and to induce remedial action, only moderate differences of composition occur.

The temperature at which samples can be "frozen out" without condensing oxygen from the air at the same time is too high to permit the collection of hydrogen or carbon monoxide, or methane unless it is present in explosive concentration. The amounts of other gases that escape condensation depend mainly on their vapor pressures at the boiling point of oxygen.

Most of the air in the cold trap after the initial sampling is removed by partial evacuation at the boiling point of nitrogen, and treatment is then given the sample to eliminate some of the carbon dioxide and water. The sample is then warmed, usually only to room temperature, and the vapors are admitted to the evacuated inlet reservoir of the mass spectrometer. In this procedure another portion of the pollutant may be lost, i. e., that which condensed from the gas phase but did not re-evaporate at the time of transfer to the spectrometer. This loss includes a portion, but not all, of each high-boiling compound that occurred in the initial atmosphere to or nearly to the point of saturation. The losses that occur both through failure to condense in the first place and to re-evaporate later are discussed in the next section.

The mass-spectrometer records a "spectrum" produced by the amplification of ion currents each of which is proportional to the total charge of ions having a single value of $M / e$, where $M$ is the sum of the atomic weights of the atoms in the ion and $e$ is the positive charge carried by it (the number of electrons removed in the ionization process). The charge is usually unity, and its measurable indication on the record is referred to as a "peak" designated by a "mass number," which is the weight of the ion with unit charge that would produce the peak. In this paper, the mass number enclosed in parentheses will indicate the ion current represented by a particu- 
lar peak, usually expressed as a percentage of the total ion current of all peaks of interest.

Chemical compounds produce ions either by the loss of an electron, leaving a "parent" peak that is only undetectably different in mass from the parent molecule, or by the loss of one or more atoms from the parent molecule, leaving a charged fragment. Each compound breaks up in a characteristic manner, producing a "pattern" by which a compound that occurs alone can almost always be identified with certainty. However, the ion currents with the same mass-to-charge ratios from a mixture of different compounds are additive. In theory at least, we could determine every compound present by the solution of an equal number of simultaneous linear equations if we had as many or more peaks on which to base the equations and patterns of all compounds involved.

All of the spectra of urban pollutants so far obtained have contained 80 or more usable peaks; but in every case there has been evidence that these peaks represented many more than 80 compounds, and their complete identification was obviously impossible. Even when a sample was separated by multiple distillations into 50 fractions, the simplest fraction still contained traces of more compounds than can be identified with certainty.

However, if we consider significant sources of pollutants, it is probable that their number is much less than that of the usable peaks, and if the products from each source are of substantially constant composition, we may be able to obtain a characteristic pattern of each and to proceed thereafter to make a fairly good estimate of the character and amount of the pollutants in terms of their sources. A procedure for making such estimates and some of the results obtained is the primary subject of this paper; but the main theme will be preceded by a discussion of sampling and laboratory procedure intended to make the analytical method understandable and essentially complete.

\section{Character of Sample Submitted to Mass Spectrometry}

As indicated in the introduction, the sample that enters the mass spectrometer contains everything that was in the gas phase in the atmosphere except (1) vapors below their concentration of saturation at the boiling point of oxygen, and (2) vapors condensed at that temperature but not re-evaporated at the time of introduction into the spectrometer. The second group of losses is discussed first.

The cold trap (Shepherd) that was generally used has a volume of about $300 \mathrm{ml}$. Typically about 100 liters of air are passed through the trap. If the atmosphere is initially saturated with a given compound, its condensate, when warmed to the initial temperature for introduction into the spectrometer, will be confined to about 0.3 percent of the volume occupied before sampling, and consequently only about 0.3 percent of the compound collected will immediately re-enter the vapor phase. However, this vapor is introduced into an evacuated and relatively large inlet reservoir of the spectrometer, and as pressure in the saturator decreases during the transfer, more of the condensate is evaporated. In the case most favorable for the detection of a highboiling compound, the freezeout tube contains only as much total volatile material as will produce a pressure satisfactory for analysis in the combined volumes of tube and inlet reservoir. In this case, the compound should be detectable if the spectrometer is only as sensitive as would be necessary to show the presence of the compound in solid or liquid form in the reservoir itself. This is the condition roughly represented on figure 1 by the notation "approximate limit of detection." Actually the freezeout tube will usually contain enough material for several spectrometer runs; the inlet reservoir will be filled from it through a passage small enough to prevent much mixing between the reservoirs, and the composition of the gas entering the inlet reservoir will not change greatly during the transfer. Sensitivity for the compound is then reduced by a factor roughly equal to the number of times the inlet reservoir can be filled from the contents of the sampling tube.

Generally a compound should be "detectable" if it occurs in the atmosphere to the extent of 5 percent of saturation and if, at the temperature of delivery into the spectrometer (assumed to be $25^{\circ} \mathrm{C}$ ), an atmosphere saturated with it would contain more than 1 part per 10 million. This statement involves a number of approximations, including the ease of forming ions from the compound, and implies that the substance contributes a measurable amount to one or more peaks that would serve for the detection and presumably the identification of the compound if nothing else were present. It does not indicate any certainty that so small a quantity of the compound can be recognized in the complicated spectrum of the total condensate.

In order to make use of this rough generalization in anticipating an indication of a compound in the mass spectrum, we need some knowledge of its approximate vapor pressure at $25^{\circ} \mathrm{C}$. Relatively few observations of vapor pressure include this temperature and those that do are scattered in the scientific literature. On the other hand, tables of boiling points for thousands of compounds occur in several commonly available textbooks. The boiling point is closely enough related to the vapor pressure at another temperature for our purpose provided there is not a change of phase between the two temperatures. Accordingly, the vapor pressure at $25^{\circ} \mathrm{C}$ was plotted with respect to the boiling point for enough substances to permit the construction of a satisfactory but entirely empirical curve, shown in two sections in figure 1.

The compounds included in this curve were chosen almost at random, and many of the vapor pressures at $25^{\circ} \mathrm{C}$ were obtained by extrapolating a formula given by the observer, often much beyond the limit of applicability specified by him. Little can be said for the plot except that the regularity shown is great 


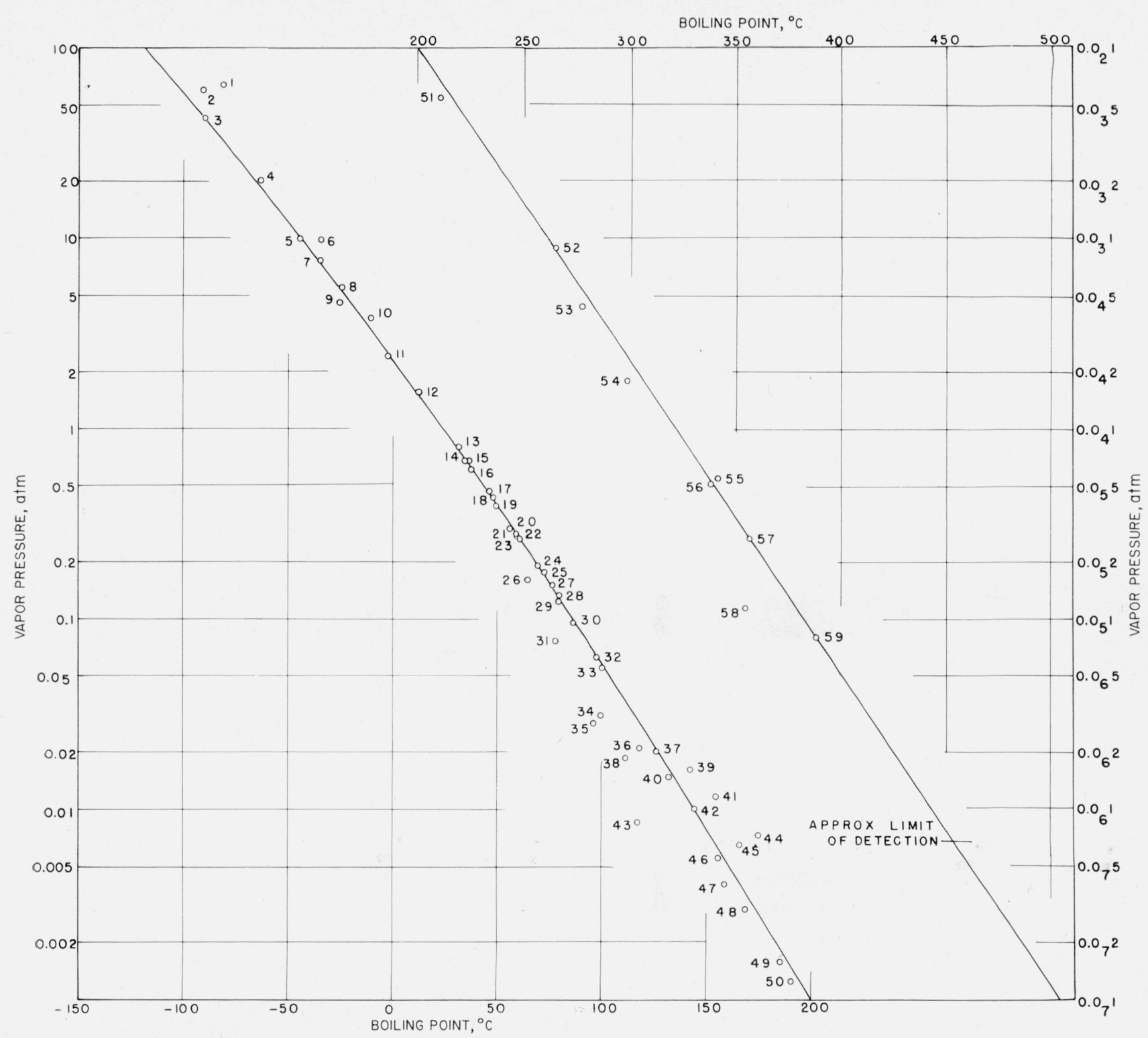

FIGURE 1. Relationship between the vapor pressure at $25^{\circ} \mathrm{C}$ and the boiling point of compounds listed in table 1.

enough to serve the purpose intended. Unfortunately, it applies only to compounds that are liquid both at the temperatures at which their vapor pressures reach $1 \mathrm{~atm}$ and at $25^{\circ} \mathrm{C}$. Table 1 is a list of the substances included in making the chart. Elements, hydrocarbons, and organic halides, fall surprisingly close, considering the accuracy claimed by the observers of the original data, to a smooth curve that is a straight line below about $0.05 \mathrm{~atm}$. Vapor pressures are notably less than would be read from the curve in the case of water, the simpler aliphatic alcohols, and some other polar compounds.

Of the 6,175 organic compounds listed in the "Ctable" of International Critical Tables, not one that is liquid at $25^{\circ} \mathrm{C}$ has a boiling point high enough to indicate that failure of its condensate to vaporize in the sampling tube would seriously interfere with the determination of its vapor in the atmosphere. Both because they are rare and because they would have to be widely dispersed to approach saturation in a significant portion of the atmosphere, it is improbable that high-boiling liquids not on the ICT list would occur as vapors in the atmosphere and then be lost in sampling. Unless all condensed liquids including water are completely vaporized in the sampler, solution would complicate the situation somewhat.

The case is different with solids. No vapor pressure data were found for any solid that did not appear below the line of figure 1 by a factor in the range from 1.5 (camphor) to $2 \times 10^{5}$ (red phosphorus). All but a few chemical substances may be expected to be in the solid form when collected at $-183^{\circ} \mathrm{C}$, and a great many of them will remain solid at room temperature. Some of these may readily escape detection although initially present in the atmosphere in greater quantity than more volatile substances that can be determined. 
TABLE 1. Compounds used in constructing figure 1

\begin{tabular}{|c|c|c|}
\hline Number & Formula & Name \\
\hline $\begin{array}{l}1 \\
2 \\
3 \\
4 \\
5\end{array}$ & $\begin{array}{l}\mathrm{CO}_{2} \\
\mathrm{~N}_{2} \mathrm{O} \\
\mathrm{C}_{2} \mathrm{H}_{2} \\
\mathrm{H}_{2} \mathrm{~S} \\
\mathrm{C}_{3} \mathrm{H}_{8}\end{array}$ & $\begin{array}{l}\text { Carbon dioxide. } \\
\text { Nitrous oxide. } \\
\text { Ethane. } \\
\text { Hydrogen sulfide. } \\
\text { Propane. }\end{array}$ \\
\hline $\begin{array}{r}6 \\
7 \\
8 \\
9 \\
10\end{array}$ & $\begin{array}{l}\mathrm{NH}_{3} \\
\mathrm{Cl}_{2} \\
\mathrm{CH}_{3} \mathrm{Cl} \\
\left(\mathrm{CH}_{3}\right)_{2} \mathrm{O} \\
\mathrm{SO}_{2}\end{array}$ & $\begin{array}{l}\text { Ammonia. } \\
\text { Chlorine. } \\
\text { Methyl chloride. } \\
\text { Methyl ether. } \\
\text { Sulfur dioxide. }\end{array}$ \\
\hline $\begin{array}{l}11 \\
12 \\
13 \\
14 \\
15\end{array}$ & $\begin{array}{l}\mathrm{C}_{4} \mathrm{H}_{10} \\
\mathrm{C}_{2} \mathrm{H}_{5} \mathrm{Cl} \\
\mathrm{HCOOCH}_{3} \\
\left(\mathrm{C}_{2} \mathrm{H}_{5}\right)_{2} \mathrm{O} \\
\mathrm{C}_{5} \mathrm{H}_{12}\end{array}$ & $\begin{array}{l}\text { Normal butane. } \\
\text { Ethyl chloride. } \\
\text { Methyl formate. } \\
\text { Ethyl ether. } \\
\text { Normal pentane. }\end{array}$ \\
\hline $\begin{array}{l}16 \\
17 \\
18 \\
19 \\
20\end{array}$ & $\begin{array}{l}\mathrm{C}_{2} \mathrm{H}_{5} \mathrm{Br} \\
\mathrm{CS}_{2} \\
\mathrm{C}_{2} \mathrm{H}_{2} \mathrm{Cl}_{2} \\
\mathrm{C}_{6} \mathrm{H}_{14} \\
\mathrm{C}_{3} \mathrm{H}_{6} \mathrm{O}\end{array}$ & $\begin{array}{l}\text { Ethyl bromide. } \\
\text { Carbon disulfide. } \\
\text { cis-Dichloroethylene. } \\
\text { 2,2-Dimethylbutane. } \\
\text { Acetaldehyde. }\end{array}$ \\
\hline $\begin{array}{l}21 \\
22 \\
23 \\
24 \\
25\end{array}$ & $\begin{array}{l}\mathrm{Br}_{2} \\
\mathrm{C}_{2} \mathrm{H}_{2} \mathrm{Cl}_{2} \\
\mathrm{CHCl}_{3} \\
\mathrm{C}_{6} \mathrm{H}_{14} \\
\mathrm{C}_{2} \mathrm{H}_{5} \mathrm{I}\end{array}$ & $\begin{array}{l}\text { Bromine. } \\
\text { trans-Dichloroethylene. } \\
\text { Chloroform. } \\
\text { Hexane. } \\
\text { Ethyl iodide. }\end{array}$ \\
\hline $\begin{array}{l}26 \\
27 \\
28 \\
29 \\
30\end{array}$ & $\begin{array}{l}\mathrm{CH}_{3} \mathrm{OH} \\
\mathrm{CCl}_{4} \\
\mathrm{C}_{4} \mathrm{H}_{9} \mathrm{O} \\
\mathrm{C}_{6} \mathrm{H}_{6} \\
\mathrm{C}_{2} \mathrm{HCl}_{3}\end{array}$ & $\begin{array}{l}\text { Methyl alcohol. } \\
\text { Carbon tetrachloride. } \\
\text { Methyl-ethyl ketone. } \\
\text { Benzene. } \\
\text { Trichloroethylene. }\end{array}$ \\
\hline $\begin{array}{l}31 \\
32 \\
33 \\
34 \\
35\end{array}$ & $\begin{array}{l}\mathrm{C}_{2} \mathrm{H}_{5} \mathrm{OH} \\
\mathrm{C}_{7} \mathrm{H}_{16} \\
\mathrm{CH}_{2} \mathrm{O}_{2} \\
\mathrm{H}_{2} \mathrm{O} \\
\mathrm{C}_{3} \mathrm{H}_{7} \mathrm{OH}\end{array}$ & $\begin{array}{l}\text { Ethyl alcohol. } \\
\text { Heptane. } \\
\text { Formic acid. } \\
\text { Water. } \\
\text { Normal propyl alcohol. }\end{array}$ \\
\hline $\begin{array}{l}36 \\
37 \\
38 \\
39 \\
40\end{array}$ & $\begin{array}{l}\mathrm{C}_{2} \mathrm{H}_{4} \mathrm{O}_{2} \\
\mathrm{C}_{8} \mathrm{H}_{18} \\
\mathrm{CCl}_{3} \mathrm{NO}_{2} \\
\left(\mathrm{CH}_{3}\right)_{2} \mathrm{C}_{6} \mathrm{H}_{4} \\
\mathrm{C}_{6} \mathrm{H}_{5} \mathrm{Cl}\end{array}$ & $\begin{array}{l}\text { Acetic acid. } \\
\text { Normal octane. } \\
\text { Chloropicrin. } \\
\text { ortho-X ylene. } \\
\text { Chlorobenzene. }\end{array}$ \\
\hline $\begin{array}{l}41 \\
42 \\
43 \\
44 \\
45\end{array}$ & $\begin{array}{l}\mathrm{C}_{9} \mathrm{H}_{12} \\
\mathrm{C}_{2} \mathrm{H}_{2} \mathrm{Cl}_{4} \\
\mathrm{C}_{4} \mathrm{H}_{9} \mathrm{OH} \\
\mathrm{C}_{10} \mathrm{H}_{14} \\
\mathrm{C}_{10} \mathrm{H}_{14}\end{array}$ & $\begin{array}{l}\text { Propyl benzene. } \\
\text { Tetrachloroethane. } \\
\text { Normal butyl alcohol. } \\
\text { Cymene. } \\
\text { Isobutyl benzene. }\end{array}$ \\
\hline $\begin{array}{l}46 \\
47 \\
48 \\
49 \\
50\end{array}$ & $\begin{array}{l}\mathrm{C}_{6} \mathrm{H}_{5} \mathrm{Br} \\
\mathrm{C}_{10} \mathrm{H}_{22} \\
\mathrm{C}_{9} \mathrm{H}_{18} \mathrm{O}_{2} \\
\mathrm{C}_{6} \mathrm{H}_{7} \mathrm{~N} \\
\mathrm{C}_{6} \mathrm{H}_{5} \mathrm{I}\end{array}$ & $\begin{array}{l}\text { Bromobenzene. } \\
\text { Dimethyl octane. } \\
\text { Isobutyl valerate. } \\
\text { Aniline. } \\
\text { Iodobenzene. }\end{array}$ \\
\hline $\begin{array}{l}51 \\
52 \\
53 \\
54 \\
55\end{array}$ & $\begin{array}{l}\mathrm{C}_{6} \mathrm{H}_{5} \mathrm{NO}_{2} \\
\mathrm{C}_{13} \mathrm{H}_{12} \\
\mathrm{C}_{12} \mathrm{H}_{10} \\
\mathrm{C}_{13} \mathrm{H}_{10} \\
\mathrm{C}_{14} \mathrm{H}_{10}\end{array}$ & $\begin{array}{l}\text { Nitrobenzene. } \\
\text { Diphenyl methane. } \\
\text { A cenaphthene. } \\
\text { Fluorene. } \\
\text { Anthracene. }\end{array}$ \\
\hline $\begin{array}{l}56 \\
57 \\
58 \\
59\end{array}$ & $\begin{array}{l}\mathrm{C}_{14} \mathrm{H}_{10} \\
\mathrm{Hg} \\
\mathrm{C}_{12} \mathrm{H}_{9} \mathrm{~N} \\
\mathrm{C}_{14} \mathrm{H}_{8} \mathrm{O}_{2}\end{array}$ & $\begin{array}{l}\text { Phenanthrene. } \\
\text { Mercury. } \\
\text { Carbazole. } \\
\text { Anthraquinone. }\end{array}$ \\
\hline
\end{tabular}

When a compound is identified, the question arises whether the percentage found in the sample that enters the spectrometer is the same as that in the original sample. If, from a knowledge of the total pressure in the sampler and the best available information on the vapor pressure of the compound at the working temperature, the sample in the cold trap appears to be saturated or nearly so, the amount shown by the mass spectrometer may be low by as much as two orders of magnitude. If saturation is not indicated in the cold trap, no loss through failure to vaporize need be assumed, but there is still to be considered the amounts of highly volatile constituents of the atmosphere that were not collected in the first place or were lost during the subsequent removal of air.

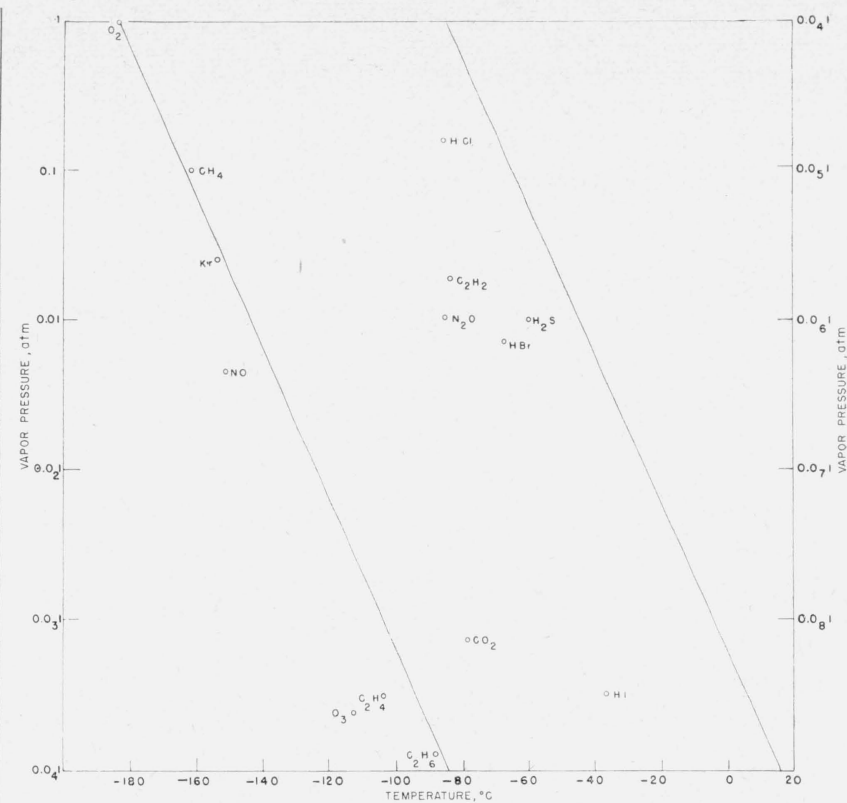

FIGURE 2. Relationship between the vapor pressure of the liquid at $-183^{\circ} \mathrm{C}$ and the boiling point.

The vapor pressure of solid substances at $-183^{\circ} \mathrm{C}$ related to the boiling point is indicated by the identified points.

The problem of loss of substance through failure to condense in the cold trap was attacked in the same way as that of failure of the condensate to vaporize, that is, by constructing a plot relating vapor pressure at $-183^{\circ} \mathrm{C}$ to the boiling point. Nearly all vapor-pressure data that could be used, even by extrapolation, relate to the liquid phase and nearly all substances are solid at the boiling point of oxygen. Liquid phase equations were extrapolated, and, as in figure 1, they gave a very consistent curve, which is a straight line within the limits of error of the data. This line has been drawn in two sections in figure 2. Extrapolated data regarding the vapor pressure of solids have been added. With the exception of methane, they lie well below the plotted line, and solution and adsorption may reduce them further. They give a rough guide for estimating the probable loss of material by failure to condense. Thus, we should not expect to collect methane unless 10 percent is present in the atmosphere. The limit for the collection of ethylene is about 30 $\mathrm{ppm}$ and for ethane $10 \mathrm{ppm}$. However, we should expect to lose only about $0.2 \mathrm{ppm}$ of acetylene, 0.1 ppm of hydrogen sulfide, and less than a part per billion of carbon dioxide. The loss of enough of anything that boils above $-20^{\circ} \mathrm{C}$ to be measurable with the mass spectrometer is improbable.

It is concluded that the delivery to the spectrometer of the vapors (1) of all substances that boil above about $-20^{\circ} \mathrm{C}$, and are liquid at $25^{\circ} \mathrm{C}$, and (2) of substances that are solid at $25^{\circ} \mathrm{C}$ and boil between $-20^{\circ}$ and $300^{\circ} \mathrm{C}$, is substantially complete. Outside this classification there may be significant loss of material at both ends of the scale of volatility. 


\section{Treatment of Sample Before Introduction Into the Mass Spectrometer}

Samples of atmospheric condensates have been treated in various ways before introduction into the mass spectrometer. The data and conclusions reported in this paper will not differentiate between the various treatments because the differences that resulted from them did not produce certainly significant changes in the interpretation of the samples to be considered. In all cases, the significant portion of the condensate must be separated from a much greater quantity of air and of condensed carbon dioxide and water. These major constituents of the unpolluted atmosphere are to be considered primarily as diluents of the sample rather than as interfering substances. As diluents they carry most of the ion current at a few mass peaks and leave the remainder of the spectrum too feeble for use. Otherwise their interference is limited to a small number of peaks shared with pollutants that can be identified in most cases, by ions of other masses.

Air is removed by evacuation while the cold trap is immersed in liquid nitrogen. Because it is impossible to remove oxygen and nitrogen completely without losing low-boiling pollutants, the evacuation is carried only far enough to control dilution. Carbon dioxide and water have been reduced to workable concentrations in several ways. These include the use of absorbing reagents ahead of the cold trap when sampling the atmosphere, freezing out a portion of water ahead of the cold trap, and the use of absorbants in the path of all of the sample between the cold trap and the spectrometer.

The treatment preferred is the following: After removing the air from the cold trap, it is allowed to warm to about $-120^{\circ} \mathrm{C}$ while connected through an Ascarite tube to a receiver immersed in liquid nitrogen. When most of the carbon dioxide has been removed in this way, the Ascarite tube is bypassed and the transfer of the sample is continued at a higher temperature, but one low enough to leave most of the water behind as ice. Preferably the ice is sublimed at least once to permit the escape of anything trapped in the original precipitate of frost. Later a higher-boiling fraction may be taken through a drying tube in the same way that the first fraction was taken through Ascarite.

\section{Numerical Arrangement of Analytical Data for Study}

The curves plotted by the mass spectrometer are reduced to numerical form by reading the "peak heights" in terms of scale divisions. The heights of the peaks considered useful are then "normalized," that is, they are added together and each peak height is expressed individually as a percentage of the total. For this purpose, certain omissions and corrections are made. The volumes of air, carbon dioxide, and water left in the sample after preliminary treatment are each still greatly in excess of the total volume of "pollutants," and their principal peaks are sometimes too high for the available scale. Even if these peaks are readable, they indicate nothing about the sample except variations in the success of the pretreatment. If they are included in the spectrum when it is normalized, two samples that contain identical pollutants will appear to be substantially different if different quantities of air, carbon dioxide, or water escaped removal. It is, therefore, convenient to include in the total for normalizing only the peaks that are subsequently to be used as significant of pollutants. For this reason Shepherd and his coworkers normalized the California samples with the omission of all peaks below (25), those between (27) and (37), and (44), (45), (46), (99), (101), and (102). To make subsequent observations comparable without recalculating the voluminous California data, the same omissions have been made in the total used in normalizing, but several peaks not included in that total are sometimes used in the interpretation of the results. These include especially (20), (22), (31), (35), (36), (45), and (46). Actually, in most cases, it makes little difference whether this group of peaks is included in the normalizing total or not as together they seldom constitute more than a fraction of 1 percent.

The omission of the principal peak of nitrogen and carbon monoxide (28), of oxygen (32), and of carbon dioxide (44) from the normalizing total and from other steps in the interpretation of the results, especially the plotting of figures, is unquestionably desirable. Little use has been made of (29) and (30), which are large peaks but seem to be nearly constant in substantially all the spectra of urban atmospheres so far studied. They are affected by isotopes related to (28) and not readily corrected for because (28) is an important peak of nitrogen, carbon monoxide, and carbon dioxide. Peak (29) represents ethyl ions which are possible fragments of a great number and variety of heavier compounds and have very little diagnostic value. Peak (30) has been given much attention, without practical result, because it contains the principal identifying peak of the nitrogen oxides and acids, and the parent peaks of ethane and formaldehyde. Figure 2 shows that nitric oxide, NO, like methane, is too volatile to be collected in the trap at any probable concentration but $\mathrm{N}_{2} \mathrm{O}$, most of which is dissociated to $\mathrm{NO}^{+}$ in the spectrometer, may be indicated. The peak is usually equal to about 9 percent of the normalizing: total, and we have been unable to attach any definite significance to its variations. Peak (40) is an important one in the spectra of many potential pollutants and is the parent peak of argon, for which a correction must be made if it is to represent pollutant and not air. The correction is based on (32). A correction of (45) and (46) for isotopes in carbon dioxide is based on (22), a doubly charged ion that distinguishes carbon dioxide from propane. Usually (99), (100), and (102) are neglected because of interference by the doubly charged isotopes of mercury that are always present. Occasionally one or more of these peaks is useful. It can usually be ascertained which peaks are significant in the study of pollution because, in the absence of pollution, they 
should all appear in the constant ratios of the mercury isotopes.

Although several attempts have been made to simplify the study of pollutants by fractionating the condensate [2], they have not been very useful because the separations are not sharp and the spectra of the fractions are almost as complex as those of the total condensates. Although further study of fractionation is planned, all data in this paper refer to total condensates only.

\section{Graphic Arrangement of Data for Study}

A great deal of use has been made of the suggestion of Sibyl Rock of the Consolidated Electrodynamics Corporation that comparisons be made between spectra by plotting them with the peaks arranged in the order of descending height in one of the spectra, called the "Reference." The peak heights are plotted on a logarithmic scale.

This method of plotting has several desirable features. The reference spectrum approaches a fairly smooth curve without maxima or minima. A spectrum compared with it shows differences of composition by deviations from the curve which, if they are at all large, take the form of a series of maxima and minima. A third spectrum shows similarities to the second by the location of the high and low points. At any peak the linear distance between the two plots represents a ratio between the abundances of the constituents that produce the ion represented. If several peaks, the (117), (119), and (121) peaks of carbon tetrachloride for example, represent only a single compound in both the reference and the sample compared with it, they all stand out equally from the reference line although they may be of greatly different magnitude. The logarithmic scale makes relative quantities of rare ions in two spectra as prominent as those of more abundant ions. This is especially important because the peaks most useful in identification are often small. These features help greatly in the identification of compounds in what seems otherwise a hopeless tangle of data. Plots are made on tracing paper so that two or more can be read when superposed, and punchings facilitate accurate registration.

In order to make convenient intercomparisons between them, all the spectra from the California samples were plotted in the order of a single spectrum designated "Ref." Ref was chosen as representative of the very similar spectra of condensates obtained in Los Angeles and Pasadena during the worst smogs that occurred in a period of 3 months in the autumn of 1951. The order of peaks in the original Ref was as follows: $43,27,41,26,42,39$, $57,56,55,70,25,58,69,71,38,91,40,78,83,37$, $84,51,50,92,53,72,45,97,85,31,98,52,54,86$, $67,68,77,111,82,65,112,49,63,95,46,106,79$, $59,81,62,130,132,60,105,74,76,73,61,47,90$, $96,66,93,64,126,87,89,114,117,119,48,75,113$, $134,94,110,120109,125,80,103,107,104,121,88$, 115,140 .

Figure 3 represents, by an envelope, the spectra of three samples taken in Los Angeles and three in
Pasadena. The envelope consists of an upper line joining points representing the highest percentage of each ion in any of the six condensates and a lower line representing the lowest percentage. The broken line between the two is Ref. The group of high peaks (117), (119), and (121), near the lower end of the plot represent carbon tetrachloride in one sample, and the peaks (64) and (48) represent sulfur dioxide in another. Both may be the result of contamination of the samples in the laboratory.

Samples taken later in various places produced other peaks below the level of detection in the samples used in the original selection of Ref. It was convenient to adopt a standard order for plotting these and other peaks, such as (29) and (30), that had been disregarded initially. This order is approximately that in which the peaks happened to become of interest, and is as follows: 128, 124, $123,127,138,139,131,129,142,136,137,118,133$, $141,108,116,147,154,151,152,156,148,149$, $143,153,146,155,145,29,30,31,35,36,99,100$, $164,165,166,168,170$. In the figures that follow, this order will be considered a part of the "order of Ref," not all of which is always used.

The plotting of peaks in other orders than that of Ref is frequently desirable. It is now the usual practice to plot a spectrum first in the order of Ref for comparison with plots of other mixtures in order to make as good a preliminary estimate as possible of what is present. The sample under study is then plotted in the order of magnitude of its own peaks, and the spectrum of the components thought to be present is built up as they are tentatively identified. This procedure gives most of the advantages of comparision with Ref, particularly the recognition of groups of peaks that indicate a single compound, and permits the modification of the tentative analysis as often as necessary with a minimum of replotting.

\section{Regularities Found in Samples From Southern California}

The most remarkable thing about the condensates obtained from the atmosphere of Southern California during smogs, was the close resemblance between their mass spectra. This is strikingly shown by the narrowness of the envelope of the six samples represented in figure 3 taken in different parts of the area during a period of 3 months. Although these samples were admittedly selected because of their close agreement, many other samples showed strong resemblances to the group and tended to show a progressive series of differences. By this is meant that the deviations from Ref were not random. Instead, differences usually appeared in much the same series of peaks, and if a certain peak height differed from that of Ref more in one sample than in another, several other peak heights showed correspondingly greater deviations in the first sample than in the second. This would, of course, necessarily be the case if the peaks considered represented a single compound; but the relationship appeared to be too general to be explained by different concentrations of 1 or 2 substances. Two explanations 


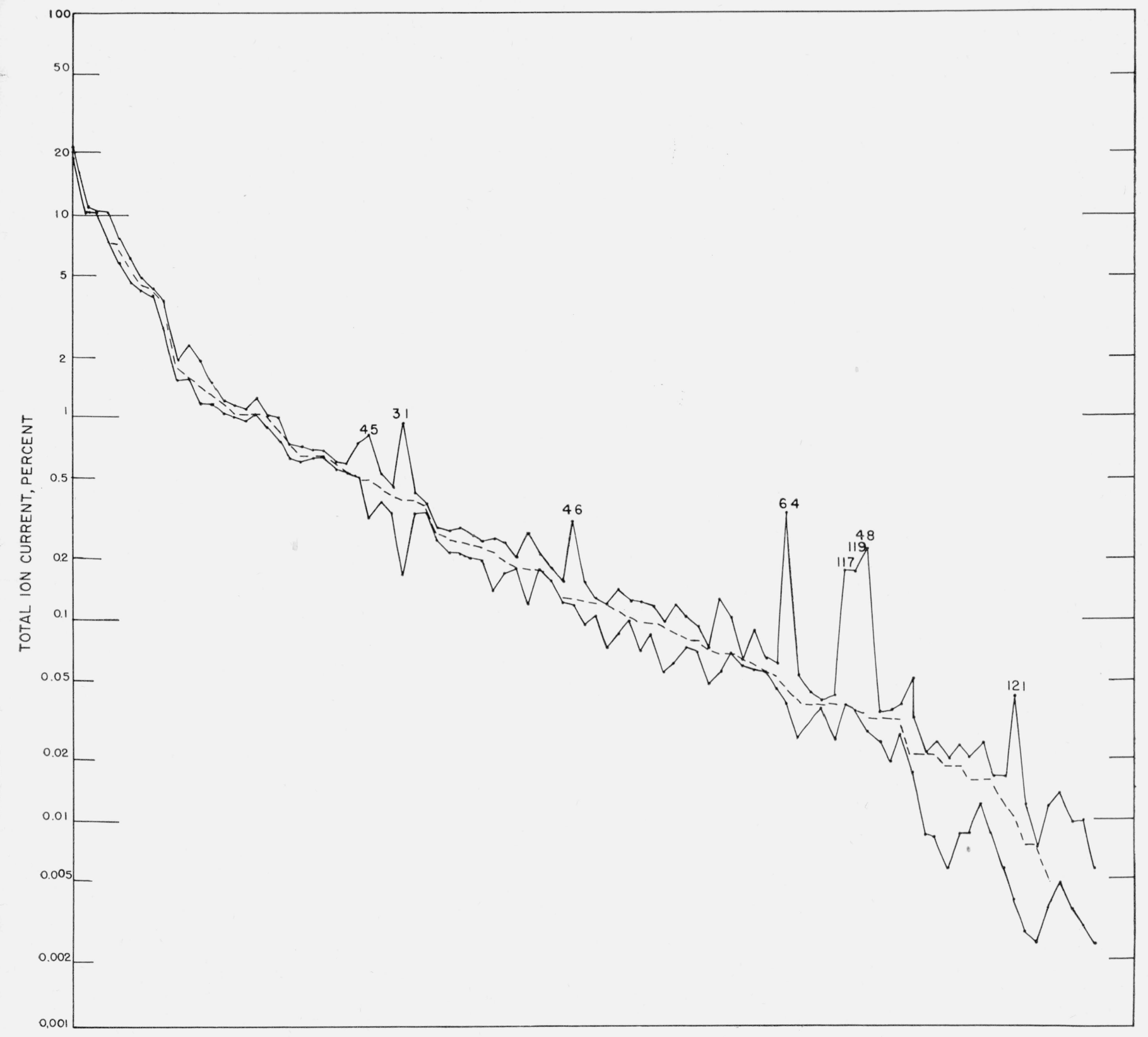

MASS NUMBER-ORDER OF Ref

Figure 3. Agreement between spectra of several condensates taken during periods of heavy smog in Los Angeles and Pasadena. , Ref.

appear probable, (1) that the atmosphere contained varying proportions of two principal groups of pollutants from different sources, or (2) that a predominant pollutant from a single source was undergoing change by reactions in the atmosphere, the progress of which was indicated by the changing spectrum. It is not surprising that local or temporary variations confused the picture considerably.

Accompanying the samples were some rather vague statem ents about weather conditions, visibility, eye irritation, etc., from which it was possible to arrange the numerous samples roughly in the order of apparent severity of smog. Each of numerous peaks and functions of peak heights, especially ratios between selected peaks, were plotted with respect to the numbers of the sample arranged in this order of apparent severity. Several of these plots indicated fairly definite trends; for example, the most abundant peak, (43), appears to increase during smog. However, the most positive trend appeared among the three ratios, $(58) /(53),(72) /(67)$, and $(86) /(81)$, all of which increased strongly and fairly consistently with increasing indications of smog. A further discussion of regularities within groups of spectra is given after the next section on "normal traffic gas." The trends mentioned in this paragraph all relate 
to the composition of the mixture of pollutants in the air and not to its over-all concentration, with which no certain correlations are apparent.

When studies of pollution in other cities were begun it was immediately evident that the spectra of their atmospheric condensates usually resembled strongly those from Los Angeles. The obvious explanation is that a large part of the pollution came from a similar source or sources; and when weather conditions and places of sampling are also considered, there appears to be nothing common to the probable origin of the pollutants except automobile traffic.

Both exhaust gas and gasoline vapor are chemically so complex that their determination as individual compounds is impossible by any means now available. But because they are released from so many vehicles, they are probably much the same everywhere; and it should be possible to treat "traffic gases" (a term intended to include an average amount of gasoline vapor from filling stations, leaks, etc.) as a unit. In order to recognize pollutants of a different character and to locate their sources, it is important to differentiate them from traffic gases as a whole. Unless we can do this, by mass spectra or otherwise, we lack the information needed to deal with the control of pollution at its various sources.

\section{Mass-Spectra Pattern of Normal Traffic Gas}

The first step was to determine with a fair degree of certainty, though not necessarily with great accuracy, the mass spectrum we may expect from traffic gas. For this purpose we had available the spectrum (A) of a sample taken from a tunnel in Pasadena in 1951 during heavy traffic, and another (B) taken in a tunnel in Washington, D. C. in 1954 under similar conditions. The Pasadena sample represented both exhaust gases and vapors from the engines, and the generally polluted atmosphere of the city drawn into the tunnel as the cars passed through, but it was reasonable to suppose that the high concentration of traffic gas would result in the outside pollution becoming negligible or nearly so. Actually, the one or two recognizable constituents of outside smog not attributable to motors indicated that about 20 percent of the total condensate collected came from outside. The Washington sample (B) was taken in a region free of industrial contamination and was believed to be almost free of pollution from any source except automobiles. Both these samples represented continuously moving traffic. To supplement them three samples were taken; (C) from a busy intersection where traffic is interrupted by lights; and (D) and (E) from points of heavy but uninterrupted traffic in residential districts. A link of a sort was established with the Southern California samples by plotting the ratios between certain peaks previously mentioned as best indicating the appearance of smog. The several samples, including two from Detroit and four from Washington, were arranged chronologically in the order of sampling. The result is figure 4 . The

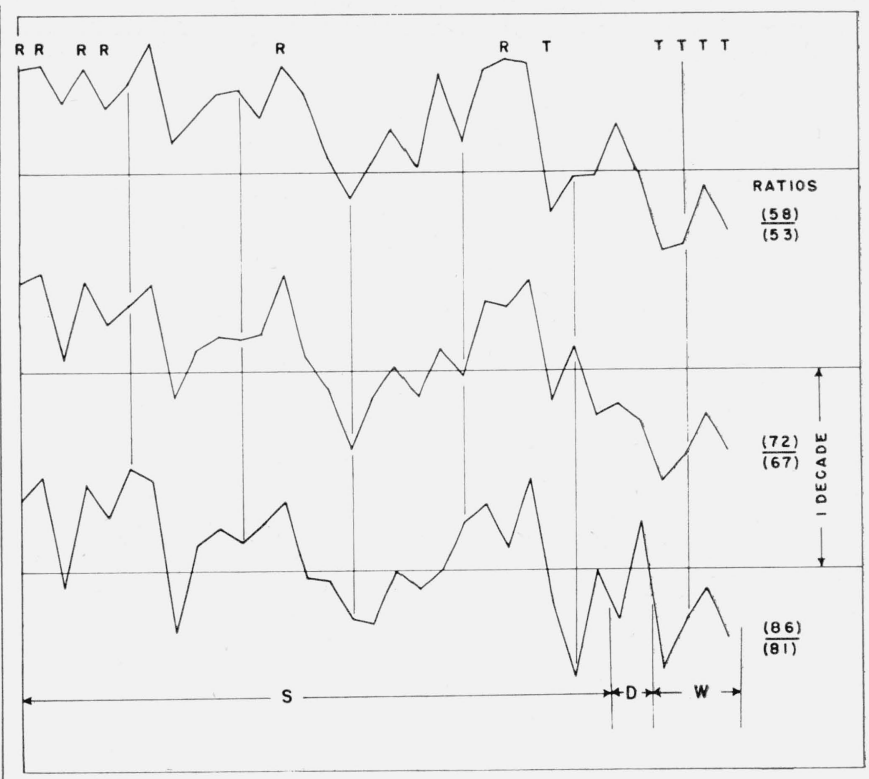

FIGURE 4. Variation in the ratio of the peak height of three pairs of mass numbers as affected by the nature of the sample.

\footnotetext{
S, Southern California; D, Detroit; W, Washington Samples used in deriving patterns: R, Ref; T, NTG
}

ordinates are logarithmic, and the curves are separated by shifting the scale 1 decade for each. Horizontal lines represent the ordinate 1.0 for the curve that intersects it. The fact that the three ratios are closely related without regard to locality is unmistakable. The six samples used to establish Ref (fig. 3) are indicated in figure 4 by the letter R, and the five samples chosen to represent normal traffic gas, by $\mathrm{T}$.

The five spectra of traffic gas were plotted and critically examined, point by point. The agreement was not as good as had been expected, and the reasons for disagreement are obscure. However, it could be assumed that if such a thing as a normal traffic gas exists, there is nothing in any of the sampling locations to remove any thing from the mixture, but it is possible, even probable, that significant additions may come from other sources. On the other hand, there is the possibility that something was lost from any of the samples during handling, by reaction, solution in stopcock lubricants, or the like. In view of these possibilities it was not believed that statistical rules of probable error would have much significance, and it was decided to consider each mass number individually and to select what seemed to be a "best value" rather than to take any kind of mathematical mean. The result is plotted with peaks in the order of the customary Ref, in figure 5 . The solid line is the selected spectrum, which will be referred to as normal traffic gas or NTG. Ref is shown as a dotted line. It must be admitted that initially no great confidence was placed in the accuracy of this picture of normal traffic gas, but subsequent use has caused greater significance to be attached to it. 


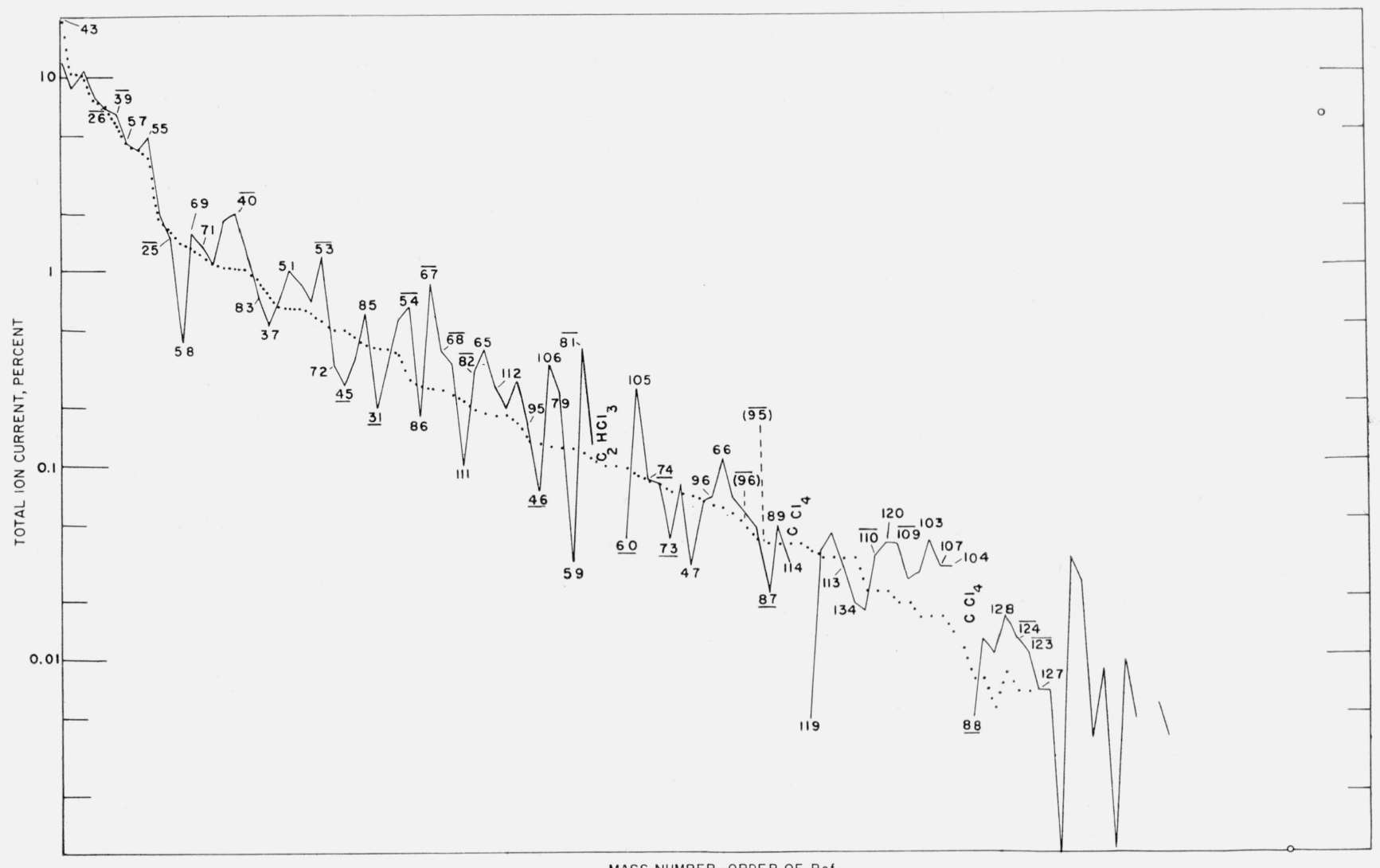

MASS NUMBER-ORDER OF Ref

Figure 5. Spectrum of normal traffic gas plotted in the same order as Ref. , NTG; ........, Ref.

\section{Comparison of Normal Traffic Gas with Ref}

A comparison of the two curves of figure 5 at once shows that compounds of certain chemical series are more abundant in one than in the other.

The members of a homologous series of compounds, for example, the paraffin hydrocarbons, differ in molecular weight by multiples of 14 . Thus methane has a molecular weight of 16 , ethane 30 , propane 44 , butane 58, etc. A positive ion formed by the loss of an electron from the molecule, called the parent ion, has the mass number of the original molecule. However, many more ions are formed from most compounds by the breaking up of molecules than by the loss of single electrons. An examination of the structural formula of any paraffin hydrocarbon will show that if it is broken in any manner into two fragments and no more, each fragment will have a mass of 1 or of 1 plus a multiple of 14 ; and that mass will be 1 less than one of the parent masses of the same series of compounds. Thus, when butane loses 1 hydrogen atom, mass (57) is left, if 1 carbon atom with its attached hydrogen (a methyl group) is detached, the residue has mass (43), 1 unit less than the parent mass of propane; detaching an ethyl group leaves 29, 1 unit less than the parent mass of ethane, etc. Although ions are also formed with the breaking of more than 1 bond of the molecule, the ions of the parent mass and of 1 less than the parent mass of some member of the homologous series, are predominant enough to be significant of the chemical nature of the parent compounds.

With this in mind, table 2 was prepared to afford a comparison of the chemical nature of the compounds represented by NTG (normal traffic gas) and Ref (the condensate from smog, assumed to be formed in considerable part, at least, by chemical reactions of traffic gas in the air). It should be noted that the same series of numbers may include the parent peaks of homologous series of compounds of quite different character.

In the following discussion it will be assumed that Ref is the product of reactions of N'TG in air rather than a mixture with things from other sources, although this can be only roughly true, and the mixture represented by $\mathrm{R}$ ef will for brevity be referred to as "oxidized" as distinguished from "normal" traffic gas. Table 2a indicates that compounds of the same parent masses as the paraffins increase in relative amount as the atmospheric reactions proceed. Because all numbers in the table are percentages of a total sample, the simplest explanation for the over-all effect is that compounds other than the paraffins are disappearing, probably with the formation of nonvolatile particles or water, carbon 
dioxide, carbon monoxide, etc., not included in the part of the spectrum considered, leaving the inert paraffins as a greater percentage of the total. However, we find that in the aggregate it is only the parent peaks that have increased. If the first explanation were the only one, the odd- and evennumbered peaks should have changed in proportion. A more interesting explanation than the first is that aldehydes and ketones are among the products of the smog-forming reactions. Aldehydes and ketones produce a much larger proportion of parent ions than do the easily broken paraffins.

Table $2 \mathrm{~b}$ shows the surprising fact that in general the peaks thought to be most characteristic of the olefins remain practically constant in relative abundance. In the literature bearing on the Los Angeles smogs the unsaturated hydrocarbons, and the olefins in particular, are given a major part of the blame for smog formation, and irradiation experiments of olefins in air have shown that the blame is not misplaced. At present no adequate explanation of the relative constancy of the "olefin peaks" has been thought of by the authors. One possibility is that most of them are derived from cycloparaffin rather than olefin sources and that the cycloparaffins remain substantially inert in the atmosphere.

Table $2 \mathrm{c}$ shows a striking decrease during smog formation of nearly all the parent and parent-minusone peaks of the group that includes acetylene and the dienes. The only exception is acetylene itself, which remains relatively constant as indicated by its parent peak, (26). The relatively smaller number of (25) ions in traffic gas may well be the effect of a reduced number of fragments of heavier molecules rather than a decrease in acetylene itself. It seems reasonably certain that the decided decrease in the other peaks in this group during conversion to smog is the result of reactions in which their parent molecules are used up.

Table $2 \mathrm{~d}$ shows a decrease in the aromatic hydrocarbons only less striking than in the preceding group, especially in the higher members of the series.

Table 2e' represents the peaks characteristic of a rather wide variety of oxygen-containing compounds, of which the alcohols, and particularly ethyl alcohol are likely to be the most abundant. Generally the peaks are not in the ratio that would indicate ethyl alcohol alone, however. This series shows such striking increases that it seems most probable that it is derived in large part from the products of traffic gases reacting in the air.

Many of the peaks in figure 5 have been labeled. Those of the series beginning with (25) and (26) are marked with a line above the number, those in the series beginning with (32) and (31) are underlined. With the exception of (25), all the 16 peaks of the first series are above Ref by surprisingly consistent amounts. A secondary regularity is to be seen in the fact that, on one side of peaks (53) and (54), which are about equally above Ref, the even-numbered peak is larger than its adjacent odd-numbered peak, whereas above (54) the reverse is true. Peaks (95) and (96) seemed out of
TABLE 2. Ratios of parent and parent-minus-one peaks

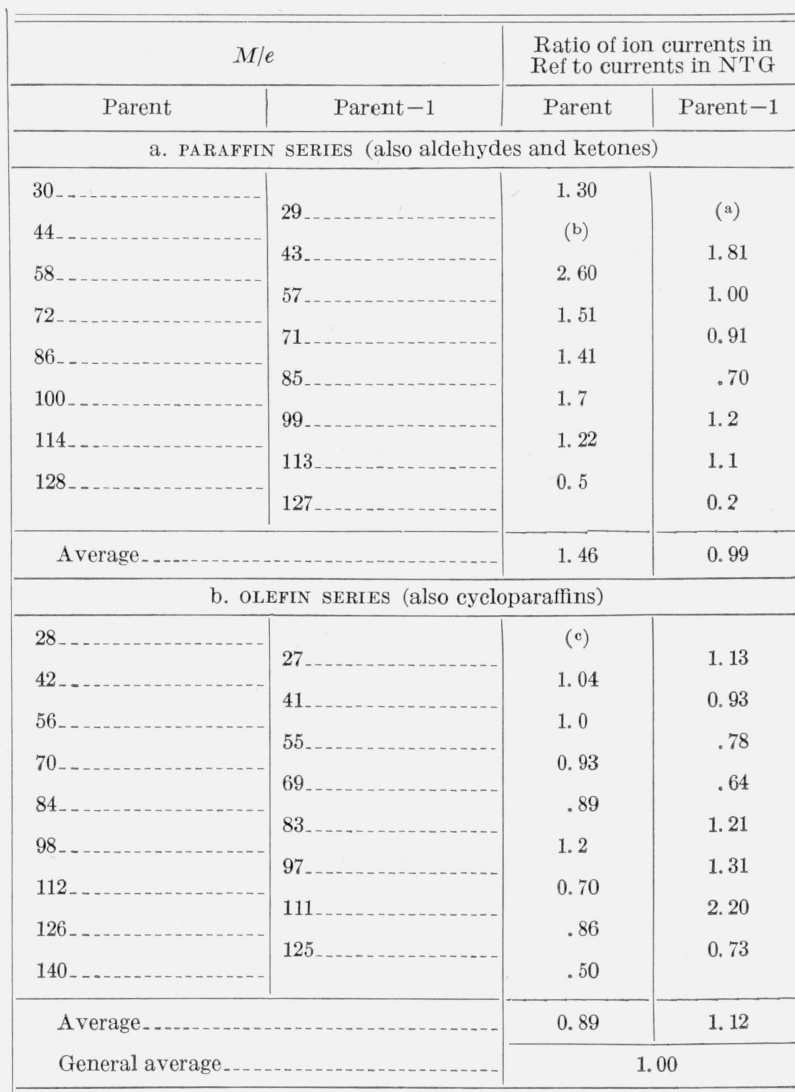

c. ACETYLENE SERIES (also dienes and cyloolefins)

\begin{tabular}{|c|c|c|c|}
\hline $26 \ldots$ & \multirow{9}{*}{$\begin{array}{l}25 \\
39 \\
53 \\
67 \\
81 \\
95 \\
109 \\
123\end{array}$} & \multirow{9}{*}{$\begin{array}{l}0.89 \\
.52 \\
.41 \\
.61 \\
.66 \\
.85 \\
.63 \\
.52\end{array}$} & \multirow{3}{*}{$\begin{array}{l}1.09 \\
0.87\end{array}$} \\
\hline $40 \ldots$ & & & \\
\hline $54 \ldots$ & & & \\
\hline $68 \ldots$ & & & .45 \\
\hline $82 \ldots$ & & & .28 \\
\hline $96 \ldots$ & & & .31 \\
\hline $110_{-}$ & & & .25 \\
\hline $124 \ldots$ & & & .48 \\
\hline & & & .61 \\
\hline \multicolumn{2}{|c|}{ Average } & 0.64 & 0.54 \\
\hline \multicolumn{4}{|c|}{ d. ONE-RING AROMATIC HYDROCARBONS } \\
\hline $78 \ldots$ & \multirow{3}{*}{$\begin{array}{l}77-\ldots+ \\
91 \\
105\end{array}$} & \multirow{3}{*}{$\begin{array}{r}0.89 \\
.89 \\
.38\end{array}$} & \\
\hline $92 \ldots$ & & & $\pi$ \\
\hline $106 \ldots$ & & & \\
\hline \multicolumn{2}{|c|}{ Average_- } & 0.72 & 0.52 \\
\hline \multicolumn{4}{|c|}{ e. ALCOHOL SERIEs (also ethers, acids, and esters) } \\
\hline 32 & \multirow{5}{*}{$\begin{array}{l}31 \\
45 \\
59 \\
73 \\
87\end{array}$} & \multirow{5}{*}{$\begin{array}{c}(\mathrm{d}) \\
1.76 \\
2.97 \\
0.95 \\
1.98\end{array}$} & \\
\hline $46 \ldots$ & & & 2.0 \\
\hline $60 \ldots$ & & & \\
\hline 74 & & & \\
\hline 88 & & & \\
\hline \multicolumn{2}{|c|}{ Average-_- } & 1.92 & 2.42 \\
\hline
\end{tabular}

a Too strong interference for use. b Obscured by carbon dioxide. ' Obscured by nitrogen. d Obscured by oxygen. 
place until it was discovered that those numbers in Ref were strongly affected by trichloroethylene. When they were corrected for the chlorine compound, they fell in the positions on the descending Ref curve marked by (), which makes them consistent with other members of the group.

Again with one exception, (74), the underlined numbers are all below the line. Peak (74) is probably affected by an interference, as (95) and (96) were, though the source of the interference has not been determined.

\section{Estimation of the Kind and Amount of Traffic Gas in a Local Situation}

It would be unreasonable to suppose that all the regularities occurring in the relation between NTG and Ref could have appeared had not the selection of the two patterns been substantially representative of two general phases of air pollution. Continuing the assumption that smog is derived primarily from traffic gas, a pollutant having the spectrum of NTG should be converted, in time, to one with the spectrum of Ref. These two spectra are so different that it is at least desirable to distinguish between them whenever a pattern for a traffic gas is used in the study of an unknown sample.

It has become a fairly well established practice in the petroleum industry to determine the various types of compounds in petroleum products, paraffins, aromatics, cycloparaffins, olefins, etc., by considering ratios between selected groups of peaks; and reported comparisons with synthetic mixtures show that high accuracy is frequently obtainable. An attempt was made to apply a similar method, using the ratios represented in figure 4 , to determine the state of reaction of the pollutants from motor traffic.

The recorded values of the several peaks (with one addition) and the computed ratios are shown in table 3.

\section{TABLE 3. Peaks principally used in judging the extent of oxidation of traffic gas}

\begin{tabular}{|c|c|c|c|c|}
\hline Peak & NTG & Ref & $\frac{\text { Ref }}{\text { NTG }}$ & $\frac{\text { NT G }}{\text { Ref }}$ \\
\hline $\begin{array}{l}(54) \\
(58) \\
(53) \\
(72) \\
(67) \\
(86) \\
(81) \\
(58) /(53) \\
(72) /(67) \\
(86) /(81) \\
\text { A verage. }\end{array}$ & $\begin{array}{c}\% \\
0.66 \\
.54 \\
1.20 \\
0.33 \\
.88 \\
.18 \\
.40 \\
.45 \\
.38 \\
.45 \\
0.43\end{array}$ & $\begin{array}{l}\% \\
0.27 \\
1.40 \\
0.54 \\
.50 \\
.25 \\
.255 \\
.121 \\
2.6 \\
2.0 \\
2.1 \\
2.23\end{array}$ & $\begin{array}{l}0.41 \\
2.6 \\
0.45 \\
1.5 \\
0.28 \\
1.4 \\
0.30 \\
-1 . \\
-.- \\
-\end{array}$ & $\begin{array}{l}2.4 \\
0.38 \\
2.2 \\
0.66 \\
3.5 \\
0.71 \\
3.3 \\
- \\
-.- \\
-\end{array}$ \\
\hline
\end{tabular}

Two approximate formulas were developed for estimating the extent of oxidation, but the rigid application of neither of them was very successful for two apparent reasons, (1) pollutants unconnected with traffic gas interfere with some of the peaks used, and (2) the reactions of oxidation do not all occur at the same rate. A rough estimate of the extent of oxidation can usually be made by plotting the spectrum of the sample in the order of Ref and comparing, preferably by superposing, with the spectra of NTG and Ref as shown in figure 5.

The total percentage of traffic gas is estimated at the same time. It will be noted that the portions of Ref and NTG between ordinates 10 and 1.5 (peaks 27 and 25 in the usual order) coincide very closely. The plot of the sample is adjusted vertically to obtain as good a fit of this portion of its curve to those of figure 5 as is practicable but with one limitation, sample peaks in other parts of the spectrum must not fall so low that their explanation would require the elimination of an unreasonable fraction of the traffic gas. Peaks much higher than either Ref or NTG should not be disturbing, in fact they are what we are looking for. When the two sets of curves have been fitted together as well as practicable, the vertical distance between the indices (ordinate 1) of the two scales shows the percentage of the total sample to be attributed to traffic gas, normal or oxidized. The fraction "X," the percentage of conversion of normal to oxidized traffic gas, is estimated by noting the relation of peak heights of the sample to those of Ref and NTG that are widely separated from one another. Peaks (53), (54), (58), (67), (72), (81), and (86) appear to be the most useful for this purpose. If maxima are not noticeable at (53), (54), (67), and (81), oxidation of the sample has proceeded far. Minima at (57), (72), and (86) are less significant because the presence of interfering substances accentuates common peaks but raises low points of the spectral curve.

Some of the peaks found in the spectra of the traffic gases are indicative of known compounds with very little probable interference. This is especially true of the parent peaks of the aromatic hydrocarbons. The aromatics are important constituents of the traffic gases and should remain a part of the total spectrum of a sample until a decision has been made as to its probable content of traffic gas. However, the aromatics can be independently determined and it would be unfortunate to have the analysis affected by their amounts in Ref or N'TG. Hence the patterns of the aromatics are "taken out" of the initial patterns of Ref and NTG, and are applied separately in the interpretation of the spectrum of the sample.

The chlorine compounds trichloroethylene and carbon tetrachloride were present in all samples used in the selection of Ref and in 2 or 3 of those used for NTG; but they are not considered normal constituents of traffic gas and they have also been taken out of the patterns of Ref and NTG. With somewhat less assurance, the patterns of ethyl alcohol, acetylene and sulfur dioxide were also taken out of the traffic gas patterns, but the spectra of these compounds are subject to so many interferences that they are determined only after most other identifiable constituents have been taken out.

While the spectrum of the sample is superposed on figure 5, a notation is made of any peaks that seem. abnormally high, and an effort is made to identify these peaks, as far as possible, with the chemical compounds they seem most likely to represent. 
Sometimes they indicate a whole group of compounds, such as gasoline vapor, in excess of that normally present in traffic gas.

The procedure is now to attempt to interpret the spectrum of the sample in the usual way except that the expurgated patterns of Ref, N'TG, and other approximately known mixtures are treated as though they represented single substances. It is helpful to plot the spectrum of the sample in the order of abundance of its own peaks, and to compare with it from time to time the composite spectrum of whatever seems to have been identified. Relations among the residual peaks are more raadily seen in graphic than in numerical form, and when the analyst has done the best he can, the remaining plot indicates at a glance how successful his effort has been.

\section{Application of the Method to a Specific Sample, Louisville D 6}

Even with the general method of approach that has been outlined, each sample presents a unique and complicated problem that is solved largely by trial and error. The interpretation of the spectrum of one sample, designated D-6, from Louisville will be followed in considerable detail to illustrate the method employed.

The spectrum of the sample was first plotted in the order Ref and the graph superposed on the patterns of both Ref and NTG, shown in figure 5 . The result is figure 6 , in which the spectrum of the sample is represented by a solid line and the two types of traffic gases by broken ones. From the agreement of the half dozen larger peaks, it is evident that the sample contains about the percentage of the more abundant hydrocarbons that is usually found in traffic gas. However, the plot also indicates that traffic gas contains much greater quantities of a large number of other things than are found in the sample, and these cannot be accounted for except by assuming that (1) there are great differences in the composition of the traffic gas in Louisville and elsewhere, or (2) that much of the major hydrocarbon fraction of the sample was derived from something other than traffic gas.

Rejecting the first assumption, the relative positions of the two plots were shifted to those of figure 7 , in which there is as good agreement among minor constituents represented by the numerous smaller peaks as seemed readily attainable. The relation between the indexes of the two plots (ordinate 1 of N'TG is in parentheses) shows that the dotted curve now represents the contribution of 30 percent of N'TG to the total spectrum. Ref has been omitted from the figure because the sample was taken early in the morning when much conversion to the condition of Ref seems unlikely and because the occurrence of high and low points in the two spectra at the same mass numbers is frequent enough to indicate normal rather than oxidized traffic gas.

If only a third of the principal group of hydrocarbons is from traffic gas, it is necessary to account otherwise for the other two-thirds. It seemed most

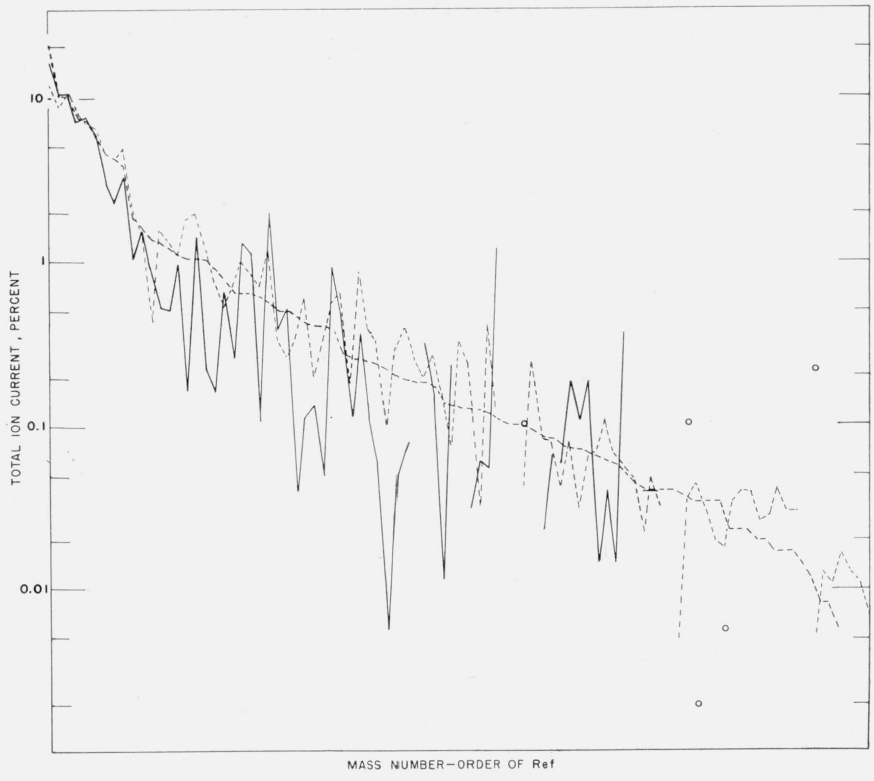

Figure 6. Comparison between Louisville sample D-6 and both Ref and normal traffic gas.

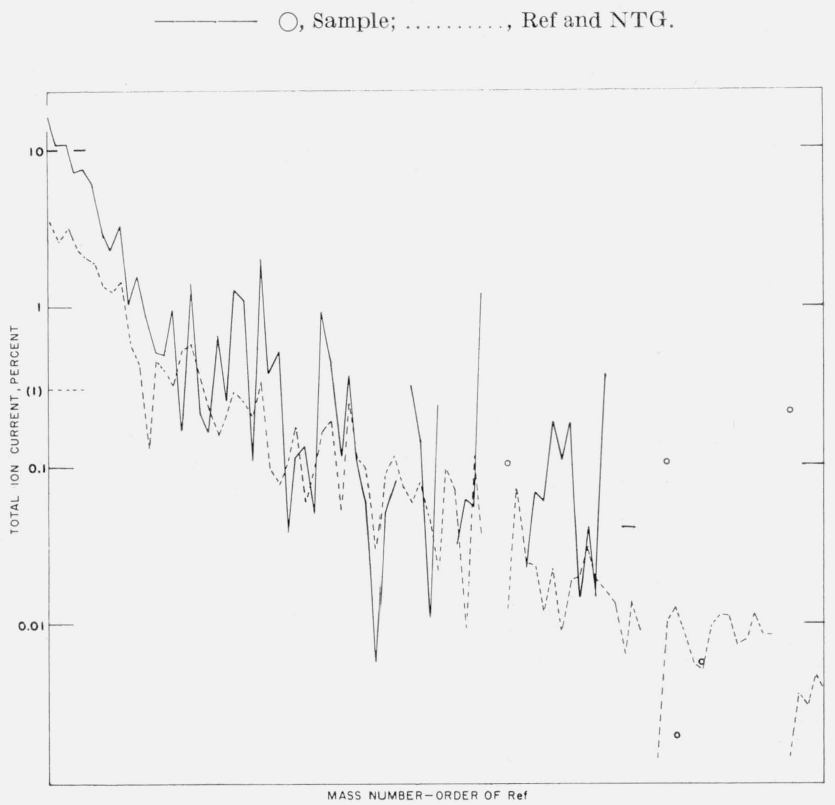

Figure 7. Contribution of normal traffic gas to the total spectrum of Louisville sample $D-6$.

$$
\text { O, Sample; ........, } 0.3 \mathrm{NTG}
$$

probable that it was raw gasoline vapor from a source not at first identified. There was available for comparison the spectrum of a composite sample of "average" gasoline from Los Angeles, made in 1951. This has a strong resemblance in the proportions among its higher peaks to the spectrum of both the sample and NTG, but the percentage of these peaks is somewhat higher than in the sample. A matching of the curves as well as practicable by superposing them in the same way that the sample and Ref were previously matched, indicated an excess in the gaso . 


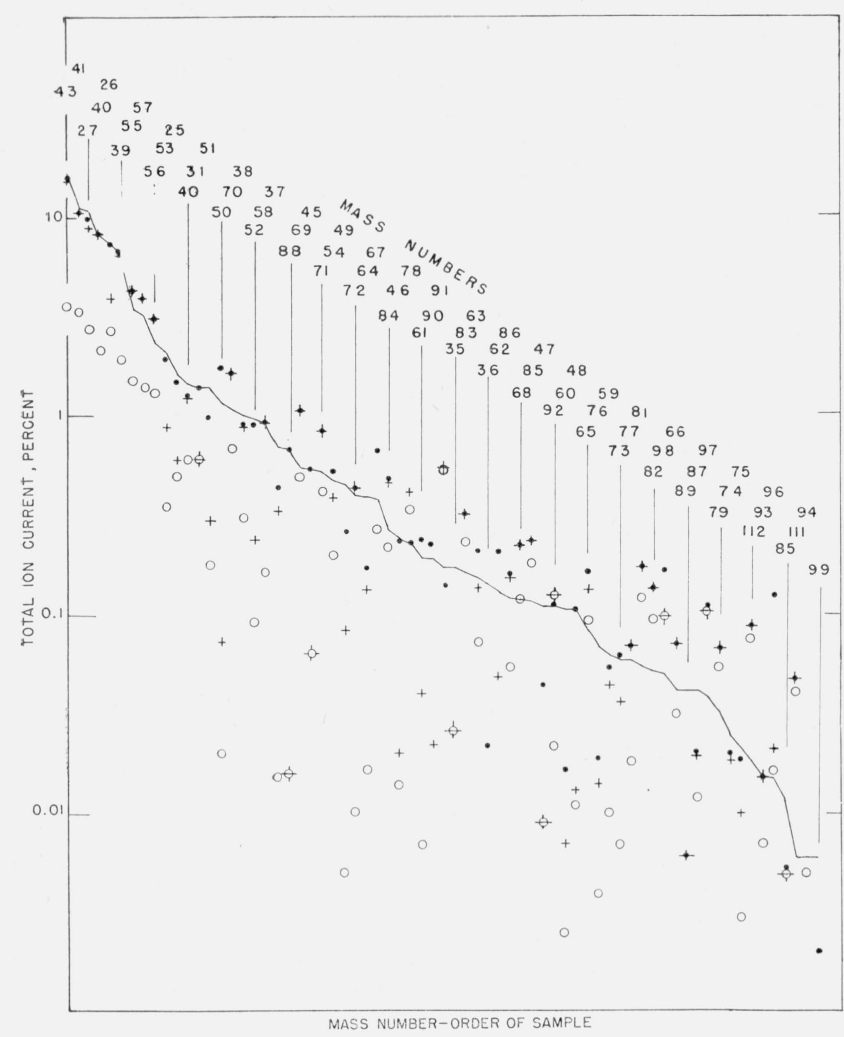

Figure 8. Total contribution of identified substances to the spectrum of Louisville sample $D-6$.

The mass numbers are plotted in descending order of their magnitude in the spectrum.

Sample. Accounted for by: $\bigcirc$, NTG $30 \%$; +, NTG $30 \%$, plus gasoline $50 \% ; \bullet$, total

line of about 25 percent. From these data it appeared that in addition to 30 percent of N'TG the sample should contain about 56 percent of gasoline vapor. A first calculation gave generally high values for the principal peaks that were high in the gasoline pattern, and the fraction assumed to be present was then rounded off to 50 percent.

In the remainder of this discussion the interpretation of the spectrum is represented by figure 8 . The sample spectrum was replotted in the order of magnitude of its own peaks. The open circles indicate the contribution to the spectrum of 30 percent of $\mathrm{NTG}^{\mathrm{T}}$, the crosses represent the sum of 30 percent NTG and 50 percent of Los Angeles gasoline vapor, and the solid dots represent the sum of everything eventually added together in the effort to account for the entire sample.

'The figure shows a great deal at a glance. The distance between a cross and the solid line indicates material to be accounted for from sources other than traffic gas and gasoline. Most of the masses at which there were large gaps to be accounted for were found to be important peaks of some of the compounds listed in advance as probable emissions from the industrial district called Rubbertown. Thus peaks (26) and (25) surely represent acetylene, (88) represents chloroprene, etc. The identification of substances that cannot be attributed to common traffic gas and gasoline, is the most important reason for assuming and applying a pattern for traffic gas. The substances identified are summarized in table 4.

It will be observed that most of the totals that are much above the line coincide with the crosses and show that the sample did not produce particular peaks as large as was expected from traffic gas and gasoline only. They are to be interpreted as meaning that the traffic gases and motor fuels whose patterns were used did not have exactly the composition of those in Louisville. This is not surprising. It is gratifying that such local differences affected as little as they did the identification and approximate determination of pollutants from other sources.

The peak heights of (78), (91), and (92), obtained by adding the patterns of NTG and gasoline and indicated by crosses, are above the dots representing "accounted for." The reason for this is that (78), the parent peak of benzene, and (92) the parent peak of toluene have no probable significant interferences, and the amount recorded by the spectrometer must, therefore, be considered to be the amount in the sample. The dot was therefore placed on the line representing the sample. None of the aromatic peaks higher than (92) was reported; accordingly (91) accounted for was calculated from (92) and the pattern of toluene. It falls somewhat below the line, indicating that there was a certain amount of aromatic material of higher molecular weight, but not enough to be reported. It is much below the (91) to be expected from NTG alone. Peaks (67) and (81) are high, possibly because the butadiene which was one of the gases from Rubbertown may have contained some higher homologs. With two exceptions, (71) and (85), the other peaks notably above the line are, in the order in which they occur in the figure, (55), (56), (70), (69), (83), (68), (98), (82), $(97),(79),(112),(96)$, and (111). All of these could be olefin peaks, but are more likely to be peaks of the cycloparaffins. Their scarcity in Louisville probably results from the fact that the California petroleums and those of Venezuela from which Washington is probably largely supplied, have high cycloparaffin contents that are lacking in the midcontinent petroleums. It was found that samples from Detroit and Cincinnati showed a similar dearth of cycloparaffin peaks, though not to the same extent as this sample which was so largely raw gasoline. It was noted that the ratio of accounted for peaks to those of the sample tends to increase with increasing mass. A possible explanation for this is the fact that most of the gasoline in Louisville probably came from a tank farm in which the vapor escaped above the liquid and was generally lighter than the liquid left behind, whereas the gasoline used as a pattern in the accounted for spectrum was completely vaporized.

Three chlorine compounds, chloroprene, vinyl chloride, and dichloroethylene, were easily identified. The first two were on the list, with hydrogen chloride and chlorine itself, of compounds to be expected from Rubbertown. Because acetylene and chlorine readily form dichloroethylene, this compound may be the product of reaction in the atmosphere. 
The dots significantly below the line represent portions of the sample spectrum, (37), (49), (64), (35), (36), (47), (76), (87), and (89) still not completely accounted for, but all or nearly all of them. are peaks that occur more abundantly in the spectra of chlorine compounds than elsewhere, and they seem to represent a background of numerous chlorine derivatives present only in very small traces.

Conclusions regarding sample D-6 are summarized in tables 4 and 5 .

The relative sensitivities of compounds are usually given in the tables of their patterns, hence relative concentrations of the identified chemical compounds need not be much in doubt. They are shown for sample D-6 in table 5. It is a major weakness of the method of analysis that no definite sensitivity can yet be assigned to the patterns of traffic gas and

TABLE 4. Interpretation of Louisville sample D-6

\begin{tabular}{|c|c|c|c|}
\hline \multicolumn{3}{|l|}{$\begin{array}{l}\text { General fractions: } \\
\text { Traffic gas }\end{array}$} & \multirow{3}{*}{\begin{tabular}{|c} 
Mole percent \\
30.00 \\
50.00
\end{tabular}} \\
\hline Gasoline vapor & 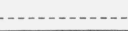 & 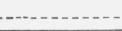 & \\
\hline Identified compounds & $\begin{array}{c}\text { Principal } \\
\text { identifying } \\
\text { peak }\end{array}$ & $\begin{array}{c}\text { Peak } \\
\text { height, } \\
\% \text { of total } \\
\text { spectrum }\end{array}$ & \\
\hline One-ring aromatic hydrocarbons: & & & \\
\hline Above $\mathrm{C}_{8} \mathrm{H}_{10}$ & 105 & None & None \\
\hline Toluene, $\mathrm{C}_{7} \mathrm{H}_{8-}$ & 92 & 0.109 & 0.17 \\
\hline Benzene, $\mathrm{C}_{6} \mathrm{H}_{6-}$ & 78 & .223 & .23 \\
\hline Terpenes_- & 93 & None & None \\
\hline $\mathrm{C}_{8} \mathrm{H}_{8}$ & 104 & None & None \\
\hline Carbon tetrachloride, $\mathrm{CCl}_{4}$ & 117 & None & None \\
\hline Trichloroethylene, $\mathrm{C}_{2} \mathrm{HCl}_{3}$ & 130 & None & None \\
\hline Chloroprene, $\mathrm{C}_{4} \mathrm{H}_{5} \mathrm{Cl}$ & 88 & 0.665 & 3.71 \\
\hline 1,3-Butadiene, $\mathrm{C}_{4} \mathrm{H}_{6}$ & 54 & .298 & 0.74 \\
\hline Acrylonitrile, $\mathrm{C}_{3} \mathrm{H}_{3} \mathrm{~N}$ & 53 & .051 & .16 \\
\hline Vinyl acetylene, $\mathrm{C}_{4} \mathrm{H}_{4-}$ & 52 & .423 & .66 \\
\hline Vinylchloride, $\mathrm{C}_{2} \mathrm{H}_{3} \mathrm{Cl}$ & 62 & .095 & .25 \\
\hline Dichloroethylene, $\mathrm{C}_{2} \mathrm{H}_{2} \mathrm{Cl}_{2}$ & 61 & .151 & .29 \\
\hline Acetylene, $\mathrm{C}_{2} \mathrm{H}_{2}$ & 26 & 6. 79 & 10. 31 \\
\hline Ethanol, $\mathrm{C}_{2} \mathrm{H}_{6} \mathrm{O}$ & 31 & 1. 32 & 2.43 \\
\hline Sulfur dioxide, $\mathrm{SO}_{2} \mathrm{~b}-$ & 48 & 0.106 & 0.67 \\
\hline Hydrogen chloride, $\mathrm{HCl}^{\mathrm{b}}$ & 36 & .141 & .38 \\
\hline Chlorine, $\mathrm{Cl}_{2} \mathrm{~b}-$ & 35 & .156 & \\
\hline
\end{tabular}

a Includes ethyl benzene.

b Not quantitatively significant of concentration in the original atmosphere because a large fraction is lost with the carbon dioxide. Chlorine and sulfur dioxide are entirely incompatible in aqueous solution and their coexistance in dioxide are entirely incompatible in aqueous solution and their coexistance in the sample to the point of introduction into the spectrometer is in some doubt.
Although chlorine and hydrogen chloride were on the list of pollutants discharged into the air by industrial plants, it is also uncertain that (35) and (36) represent these two gases rather than unidentified organic compounds containing cblorine.

TABLE 5. Approximate concentrations of identified compounds in Louisville sample $D-6$

Column A-Height of identifying peak ( $\%$ of total ion current).

Column B-Ratio of sensitivity of identifying peak to base peak.

Column C-Ratio of sensitivity of base peak to base peak of butane.

Column D-A number proportional to mole fraction of identified compound=

Column D-A numb.

Column E-Mole fraction of pollutant if identified compounds are assumed to aggregate $20 \%$

\begin{tabular}{|c|c|c|c|c|c|}
\hline Compound & A & $\mathrm{B}$ & $\mathrm{C}$ & $\mathrm{D}$ & $\mathrm{E}$ \\
\hline Toluene_- & 0.109 & 0.77 & 1.17 & 0.12 & 0.17 \\
\hline Benzene........ & .223 & 1.00 & 1. 36 & .16 & .23 \\
\hline Chloroprene...-- & .665 & 1.00 & 0.26 & 2.55 & 3.71 \\
\hline 1,3-Butadiene... & .298 & 0.88 & .67 & 0.51 & 0.74 \\
\hline Ácrylonitrile...... & .051 & .90 & .50 & .11 & .16 \\
\hline Vinyl acetylene .... & .423 & 1. 00 & .95 & .45 & .66 \\
\hline Vinyl chloride.-. & .095 & 0.76 & .74 & .17 & .25 \\
\hline Dichloroethylene... & .151 & 1.00 & .74 & .20 & .29 \\
\hline $\begin{array}{l}\text { Acetylene, total } \\
\text { (from industrial sources) }\end{array}$ & 6.79 & 1. 00 & .96 & 7. 08 & 10.31 \\
\hline $\begin{array}{l}\text { Ethanol, total } \\
\text { (from industrial sources) }\end{array}$ & 1. 32 & 1.00 & .79 & 1. 67 & $\begin{array}{l}2.43 \\
1.34\end{array}$ \\
\hline Sulfur dioxide & 0.106 & 0.49 & .47 & 0.46 & ะ 0.67 \\
\hline Hydrogen chloride & .141 & 1.00 & .54 & .26 & a. 38 \\
\hline Chlorine & .117 & $-\cdots$ & $-\ldots$ & -...- & -...- \\
\hline & & & Total & 13. 74 & 20.00 \\
\hline
\end{tabular}

a Not quantitatively significant for the reason stated in footnote (b) of table 4 . gasoline, and this makes it impossible to determine with accuracy even the relative mole fractions of these mixtures and of the individually identified compounds. In preparing table 5, it was assumed that the 13.74 percent of the ion current carried by "identified" compounds represented a 20 mole percent of the sample, and that the remaining 86.26 percent of the ion current represented an 80 mole percent of traffic gas and gasoline. It follows that for the traffic gas and gasoline $\mathrm{BC}=1.08$; that is, unit volumes of their mixture contribute as much to the ion current in the spectrometer as 1.08 volumes of butane.

\section{Louisville Sample ST-1}

Other samples from Louisville can be reported in much less detail. Several of them present points of special interest, however.

Sample ST-1 was taken from 9 to $10 \mathrm{p}$. m. in the West End of Louisville at a time of very little air movement, the direction of which was not definitely determined. The ratios plotted for other samples in figure 4 and often used in judging the percentage of change from NTG to Ref, were all lower than for NTG itself. This, and the fact that the sample was taken after sunset combine to make any previous photochemical reaction in the atmosphere improbable. From a comparison of a plot of the sample with one of NTG, it was estimated that 85 percent of the sample was traffic gas, but as the interpretation of the spectrum progressed this estimate was changed to 75 percent.

The procedure illustrated in figure 4 was followed. The spectrum of the sample was plotted in the order of its own peak heights and initially compared with the sum of N'TG and the aromatic hydrocarbons indicated by their parent peaks. Among the peaks prominent as "unaccounted for" at this stage were (93), (94), (107), and (108) which were thought to represent phenolic compounds; (47), (49), and several other pairs of peaks two mass units apart, interpreted to represent chlorine compounds; and (55), (56), (69), (70), and others that seemed to represent a concentration of olefin or naphthene compounds much too great to be explained by traffic gas.

It appeared probable that the prominent (108) and (93) peaks should be attributed to cresol, $\mathrm{CH}_{3} \mathrm{C}_{6} \mathrm{H}_{4} \mathrm{OH}$. No pattern was available until a sample of commercial "Cresol, U. S. P." was run to provide one. This gave a spectrum containing some ions too heavy for pure cresol and much more (94) than seemed likely to be formed in quantity from a compound with a parent mass of (108). It was, therefore, decided to take out the pattern of phenol from that of the Cresol, U. S. P. and to consider the remainder to be the pattern of everything in cresol heavier than phenol. Phenol and cresol, based on (94) and (108), were then taken out of the spectrum of the sample. There still remained a large (93) to be accounted for. Terpenes, in particular the pinenes, seemed to offer the only patterns that would account for (93) without large deficits in other peaks, and the (93) was accordingly attributed to pinene. 
Two other easily recognizable but complex groups of compounds were obviously present: (1) Chlorine derivatives and (2) unsaturated hydrocarbons, apparently mostly of the olefin series, but with some acetylene or diene members. These were clearly not from the same sources in Rubbertown that supplied the chief pollutants of sample D-6; for example, chloroprene was present only as a trace, if at all, and there was no evidence of acrylonitrile, vinyl compounds, or of gasoline in excess of that to be attributed to traffic gas.

The possible number of compounds that might have been constituents of either the chlorinated or the unsaturated groups of pollutants is many times greater than the number of peaks available for their identification; a complete analysis in terms of individual chemical compounds is accordingly out of the question, just as is that of the hydrocarbons of traffic gas. However, some of the constituents are almost certainly identifiable, and the general nature of the two groups seems fairly certain to be that indicated in table 6 , both in chemical character, and approximate molecular weight.

The actual order of taking out the various substances was as follows: Cresol, phenol, $\mathrm{C}_{9} \mathrm{H}_{12}$, and other aromatic hydrocarbons heavier than xylene, $\mathrm{C}_{8} \mathrm{H}_{10}$ representing the xylenes and ethylbenzene, styrene, toluene, benzene, NTG, a mixture of alphaand beta-pinene in equal proportions, ethanol, dichloroethylene, dichloromethane, methyl chloride, trichloromethane, dichloroethane, dichloropropane, 3-methyl-1-pentene, 3-hexyne, cis-2-pentene, and finally isohexane (2-methyl pentane). After the last of the unsaturated hydrocarbons had been taken out, there remained prominent peaks at (86) and (71) in a ratio that corresponds to isohexane, which was then taken out. To have attributed (86) and (71) to gasoline vapor of the composition assumed in the case of sample D-6 would have produced serious deficits in other peaks, particularly (72). Several other possibilities were considered but led to

TABLE 6. Interpretation of spectrum of Louisville sample ST-1

\begin{tabular}{|c|c|c|c|}
\hline Substance & $\begin{array}{c}\text { Principal } \\
\text { identi- } \\
\text { fying } \\
\text { peak }\end{array}$ & $\begin{array}{c}\text { Peak } \\
\text { height, } \\
\% \text { of total } \\
\text { spectrum }\end{array}$ & $\begin{array}{c}\text { Mole } \\
\text { fraction } \\
\%\end{array}$ \\
\hline Normal traffic gas_. & - & & 75 \\
\hline Phenolic compounds: & & & \\
\hline Cresol, $\mathrm{C}_{7} \mathrm{H}_{8} \mathrm{O}$ & 108 & 0.552 & 1.84 \\
\hline Phenol, $\mathrm{C}_{6} \mathrm{H}_{6} \mathrm{O}$ & 94 & .151 & 0.66 \\
\hline One-ring aromatic hydrocarbons: & & & \\
\hline Above, $\mathrm{C}_{8} \mathrm{H}_{10}$ & 105 & .973 & .97 \\
\hline $\mathrm{Xylenes,} \mathrm{C}_{8} \mathrm{H}_{10}$ and ethyl benzene... & 106 & .369 & .67 \\
\hline Toluene, $\mathrm{C}_{7} \mathrm{H}_{8}$ & 92 & 1. 68 & 2.95 \\
\hline Benzene, $\mathrm{C}_{6} \mathrm{H}_{6}$ & 78 & 1. 79 & 1.32 \\
\hline Styrene, $\mathrm{C}_{8} \mathrm{H}_{8} \ldots$ & 104 & 0.030 & 0.027 \\
\hline Terpenes: & & & \\
\hline Pinenes, $\mathrm{C}_{10} \mathrm{H}_{16 \ldots}$ & 93 & .801 & .78 \\
\hline $\begin{array}{l}\text { Unsaturated hydrocarbons not ac- } \\
\text { counted for by NTG: }\end{array}$ & & & \\
\hline 3-Methyl-1-pentene, $\mathrm{C}_{6} \mathrm{H}_{12}$ & 84 & .460 & 1.80 \\
\hline 3 -Hexyne, $\mathrm{C}_{6} \mathrm{H}_{10}$ & 82 & .336 & 0.61 \\
\hline cis-1-2-Pentene, $\mathrm{C}_{5} \mathrm{H}_{10}$ & 70 & .500 & 1. 67 \\
\hline Isohexane, $\mathrm{C}_{6} \mathrm{H}_{14}$ & 71 & .500 & 1.20 \\
\hline Ethanol, $\mathrm{C}_{2} \mathrm{H}_{5} \mathrm{OH}$ & 31 & 1. 92 & 2.94 \\
\hline Aliphatic chlorine compounds: & & & \\
\hline Methyl chloride, $\mathrm{CH}_{3} \mathrm{Cl}_{\text {. }}$ & 50 & 0.40 & 0. 76 \\
\hline Dichloromethane, $\mathrm{CH}_{2} \mathrm{Cl}_{2 \ldots}$ & 49 & .250 & .42 \\
\hline Chloroform, $\mathrm{CHCl}$ & 93 & 281 & 1. 23 \\
\hline Dichloroethane, $\mathrm{C}_{2} \mathrm{H}_{4} \mathrm{Cl}_{2}$ & 62 & .303 & 0.51 \\
\hline Dichloropropane, $\mathrm{C}_{3} \mathrm{H}_{6} \mathrm{Cl}_{2}$ & 111 & .126 & .13 \\
\hline Dichloroethylene, $\mathrm{C}_{2} \mathrm{H}_{2} \mathrm{Cl}_{2} \ldots$ & 61 & .10 & .14 \\
\hline
\end{tabular}

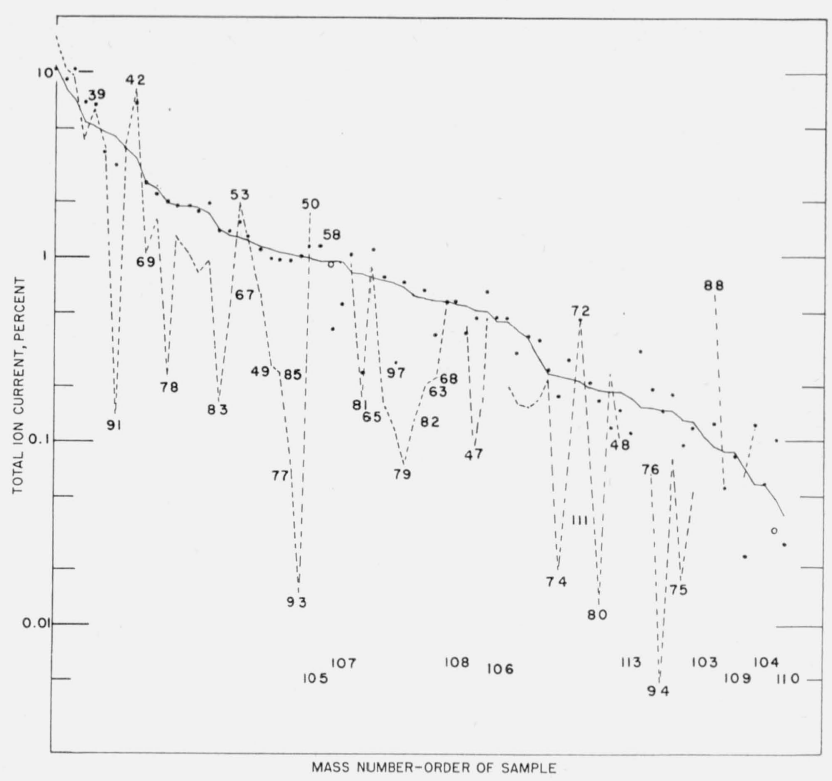

FIgURE 9. Total contribution of identified substances to the spectrum of Louisville sample ST-1.

, Accounted for; $\bigcirc \ldots \ldots . .$. , sample D-6-Fo; ——, sample S T-1

similar difficulties. It seemed most likely, therefore, that there existed some source of fairly isolated isohexane, perhaps used as an intermediate in chemical manufacture or as a solvent.

Other residuals are either too small to be of probable significance, are of uncertain origin, or are probable fragments of parent molecules too heavy to have been included in the recorded spectrum. Thus (58) may represent propionaldehyde, acetone, or unaccounted for butane; (81) is probably a fragment of an unidentified diene or acetylene derivative with a molecular weight of (96) or more; and (95) and (97) are probably derived largely from unidentified chlorine compounds with at least 2 carbon and 3 or more chlorine atoms.

Figure 9 shows the degree of agreement reached in accounting for the sample, in this case by the relation of solid dots to the unbroken line. As a matter of interest, a broken line was added to show the spectrum of D-6 plotted in the same order. The large differences between these two samples is in striking contrast to the generally close agreement among southern California samples, illustrated in figure 3, The numbers above the solid line identify peaks much higher in D-6 than in ST-1, those below the line those that were much lower. Numbers below breaks in the dotted curve represent mass numbers not reported in sample D-6. It is probable that the small peaks attributed to fragments of unidentified chlorine compounds in D-6 came from the same general source as the aliphatic halogen derivatives in ST-1 during a brief shift of wind direction.

\section{Analysis of Louisville Sample X-1}

Sample $\mathrm{X}-1$ (fig. 10) shows several points of interest. Whereas the major hydrocarbons' pattern of ST-1 is well accounted for by normal traffic gas, 


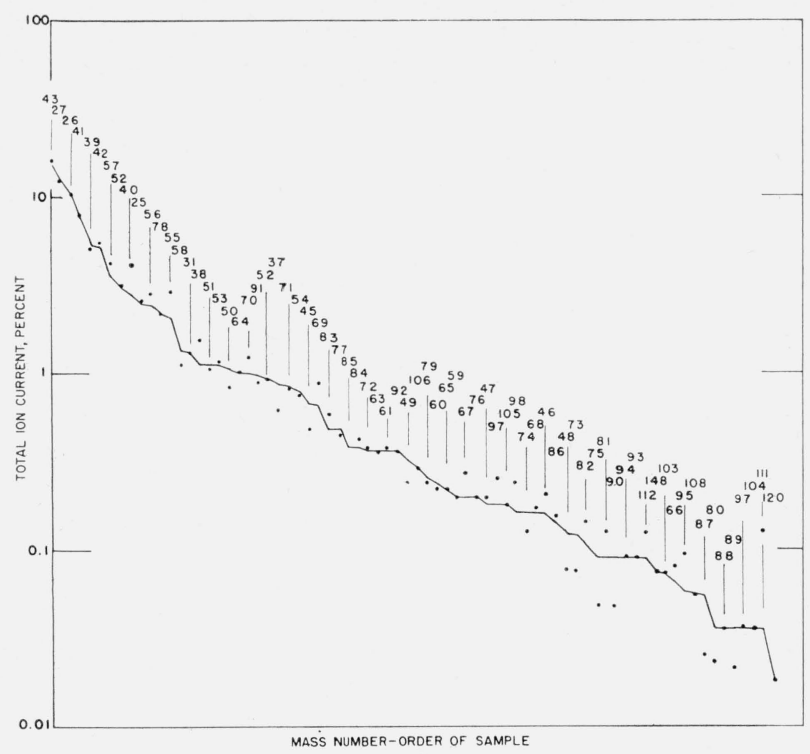

Figure 10. Total contribution of identified substances to the spectrum of Louisville sampe $X-1$.

$\longrightarrow$, Sample; .........., accounted for.

and that of D-6 indicates the presence of a major amount of raw gasoline vapor, the pattern of $\mathrm{X}-1$ is best accounted for by the use of Ref and the assumption that oxidation of traffic gas had proceeded nearly as far as in the Los Angeles smogs. The analysis was eventually based on the assumption that the sample was two-thirds traffic gas which had undergone a 75 percent conversion to Ref.

Industrial impurities included the group of pollutants, in sample D-6, attributed to Rubbertown, ethyl alcohol, and a definite though not large portion of phenol and cresol, presumably from the same source as the same compounds in $\mathrm{ST}-1$. The amount of (93) unaccounted for by toluene, phenol, and cresol was negligibly small and much less in proportion to these compounds than in ST-1. This may indicate that the terpenes in ST-1 were from a source other than that of the cresol, although it was at first assumed that they represented effluents from the same plant. Evidence of either the numerous group of chlorinated aliphatic compounds or the olefins in ST-1 is lacking in $\mathrm{X}-1$.

Table 7 lists the compounds identified in $\mathrm{X}-1$. Both normal butane and normal pentane are undoubtedly constituents of Ref. Their inclusion in the accounting as additional to the usual pattern of Ref is an accounting device and does not necessarily indicate that they were isolated pollutants. They may indicate some admixture of gasoline vapor from the same source as that in $\mathrm{D}-6$ but not distinguishable as such, and the evidence of butane could be almost as well interpreted as acetone. However, a strong indication of butane occurs in several Louisville samples, and it may be an industrial pollutant distinct from gasoline. The identifications of carbon disulfide, fluorotrichloromethane (Freon 11), tertiary-butyl alcohol, and pentyl benzene are based each on a single peak and may be
TABLE 7. Interpretation of Louisville sample $X-1$

\begin{tabular}{|c|c|c|c|}
\hline Substance & $\begin{array}{l}\text { Principal } \\
\text { identi- } \\
\text { fying } \\
\text { peak }\end{array}$ & $\begin{array}{l}\text { Peak } \\
\text { height, } \\
\% \text { of total } \\
\text { spectrum }\end{array}$ & $\begin{array}{c}\text { Mole } \\
\text { fraction } \\
\%\end{array}$ \\
\hline $\begin{array}{l}\mathrm{NTG}_{\ldots} \\
\text { Ref..... }\end{array}$ & $\ldots$ & & $\begin{array}{l}16 \\
50\end{array}$ \\
\hline Pentyl benzene, $\left\{\begin{array}{l}\left(\mathrm{C}_{11} \mathrm{H}_{16}\right) \ldots \\
\mathrm{C}_{9} \mathrm{H}_{12} \ldots\end{array}\right.$ & $\begin{array}{l}148 \\
120\end{array}$ & $\begin{array}{r}0.073 \\
.018\end{array}$ & $\begin{array}{r}0.45 \\
.06\end{array}$ \\
\hline $\begin{array}{l}\text { Xylene, } \mathrm{C}_{8} \mathrm{H}_{10} \\
\text { Toluene, } \mathrm{C}_{7} \mathrm{H}_{8} \\
\text { Benzene, } \mathrm{C}_{6} \mathrm{H}_{6}\end{array}$ & $\begin{array}{r}106 \\
92 \\
78\end{array}$ & $\begin{array}{r}.291 \\
.304 \\
2.19\end{array}$ & $\begin{array}{r}.73 \\
.55 \\
3.02\end{array}$ \\
\hline $\begin{array}{l}\text { Cresol, } \mathrm{CH}_{3} \mathrm{C}_{6} \mathrm{H}_{4} \mathrm{OH} \\
\text { Phenol, } \mathrm{C}_{6} \mathrm{H}_{5} \mathrm{OH}_{2} \\
\text { Styrene, } \mathrm{C}_{8} \mathrm{H}_{8} \\
\text { Chloroprene, } \mathrm{C}_{4} \mathrm{H}_{5} \mathrm{Cl} \\
\text { Vinyl chloride, } \mathrm{C}_{2} \mathrm{H}_{3} \mathrm{Cl}\end{array}$ & $\begin{array}{r}108 \\
94 \\
104 \\
88 \\
62\end{array}$ & $\begin{array}{r}0.053 \\
.080 \\
.015 \\
.031 \\
3.164\end{array}$ & $\begin{array}{r}0.08 \\
.11 \\
.02 \\
.06 \\
8.51\end{array}$ \\
\hline $\begin{array}{l}\text { 1,3-Butadiene, } \mathrm{C}_{4} \mathrm{H}_{6} \\
\text { Acrylonitrile, } \mathrm{C}_{3} \mathrm{H}_{3} \mathrm{~N} \\
\text { Normal pentane, } \mathrm{C}_{5} \mathrm{H}_{12} \\
\text { Normal butane, } \mathrm{C}_{4} \mathrm{H}_{10} \\
\text { Ethyl alcohol, } \mathrm{C}_{2} \mathrm{H}_{5} \mathrm{OH}\end{array}$ & $\begin{array}{l}54 \\
53 \\
72 \\
43 \\
31\end{array}$ & $\begin{array}{r}0.408 \\
.267 \\
.078 \\
2.502 \\
1.309\end{array}$ & $\begin{array}{l}1.76 \\
0.91 \\
.12 \\
3.80 \\
2.24\end{array}$ \\
\hline $\begin{array}{l}\text { Acetylene, } \mathrm{C}_{2} \mathrm{H}_{2} \\
\text { Carbon disulfide, } \mathrm{CS}_{2} \\
\text { Fluorotrichloromethane, } \mathrm{CFCl}_{3} \\
\text { Tertiary butyl alcohol, } \mathrm{C}_{4} \mathrm{H}_{9} \mathrm{OH}_{-}\end{array}$ & $\begin{array}{r}26 \\
76 \\
103 \\
59\end{array}$ & $\begin{array}{r}5.142 \\
0.125 \\
.013 \\
.073\end{array}$ & $\begin{array}{r}10.70 \\
0.13 \\
.03 \\
.14\end{array}$ \\
\hline
\end{tabular}

in error. The first three are products commonly used in chemical industry, and their occurrence in detectable amounts seemed more probable than that of other compounds found to have patterns that could be fitted readily into the picture. No pattern was available for pentylbenzene, and its assignment was based on the following facts: (1) There was a small but significant peak at (148) but none were observed at (133) or (119); (2) mass (148) is one of the series of parent peaks of benzene rings with paraffin side chains, with which there is usually very little interference from other compounds; (3) from the parent molecular weight, there must be five sidechain carbons; (4) an inspection of the patterns of other benzene-paraffin hydrocarbons shows that they tend to fragment by breaking away alkyl groups. They are prone especially to lose the alkyl group or, in the case of toluene, hydrogen from the carbon attached to the benzene ring; (5) if a methyl group were attached to the ring we should expect a major peak at (133), if ethyl, at (119). The absence of both these peaks indicates that the side chain must be pentyl; (6) the (91) peak which we should expect to be the most prominent in the case of the pentyl benzene is not otherwise fully accounted for. Sensitivity was estimated from sensitivities of the parent peaks of other aromatic hydrocarbons.

Peaks that are significantly over-accounted for again contain a disproportionate number that are attributable to cycloparaffins in the traffic gas patterns. The excess of peak (40), which includes argon based on oxygen in the sample, may have been affected by the initial liquefaction of a small amount of oxygen when the sample was taken. Among the ions not completely accounted for, (49) and (50) are prominent. This is of interest because the same two peaks appear prominently in the unaccountedfor portions of several Louisville samples. They suggest the presence of biacetylene, $\mathrm{C}_{4} \mathrm{H}_{4}$, but this is a relatively rare compound that would not be expected to appear in significant amount. 


\section{Other Louisville Samples}

Several other samples taken in different parts of Louisville during a period of clear weather with little wind are summarized in table 8 , and the result of the final accounting is presented in figures 11 to 15 .

Sample G-1, figure 11, was very largely traffic gas, apparently a little less than half oxidized, with the addition of a rather large amount of acetylene. Although the aromatics and alcohol were reported separately because their determination is independent of traffic gas, they were less than are usually found in traffic gas. The only evidence of pollution from Rubbertown consisted of traces of vinyl chloride and dichloroethylene such as might have been carried by an atmospheric swirl of short duration. Of the peaks not fully accounted for, (49) and (50) were again the most prominent, and cycloparaffins as indicated by peaks (69), (70), (83), (84), (97), (98), (111), and (112) were again overaccounted for. Difluorodichloromethane was introduced into the sample during laboratory operations and will not be mentioned in the discussion of other samples in which it occurred; but the small amount of carbon tetrachloride is believed to have been from a Louisville source. The sample, on the whole, was a typical traffic gas almost free of industrial contamination.

Sample G-2, figure 12 was almost like $\mathrm{G}-1$. The sample was traffic gas apparently about one-eighth oxidized and entirely without evidence of industrial pollution, if we except a small amount of tetrachloroethylene and the unidentified constituent represented by peaks (49) and (50). To permit a comparison of some constituents computed directly from the spectrum of G-2 and independently from the patterns used for traffic gas, the latter have been marked with X at masses (78), (92), (106), and (31), masses which are usually significant of benzene, toluene, xylene, and alcohol, respectively.

Sample G-3, figure 13, was again traffic gas only slightly oxidized and free of the usual industrial contamination of the city, but strongly polluted with carbon tetrachloride and a little chloroform. Peaks (49) and (50) were again high, though not much so, and (59), attributed to tertiary butyl alcohol in sample $\mathrm{X}-1$, was again prominent.

The traffic gas of $\mathrm{G}-5$, figure 14 , was about 40 percent oxidized. There was evidence of industrial pollution and on the basis of previous samples, it was thought to come from at least four separate sources. The industrial pollutants identified were cresol, phenol, chloroprene, carbon tetrachloride, and dichloromethane. Acetylene and alcohol were not in excess of the usual content amount in traffic gas.

Sample G-6, figure 15, appeared to have a base of about 40 percent of completely oxidized traffic gas (Ref), and 15 percent of gasoline vapor. It contained small amounts of the Rubbertown pollutants, chloroprene, butadiene, acrylonitrile, and acetylene, less of cresol, phenol, and pinene. There were methyl chloride, carbon tetrachloride, tetrachloroethylene, and some evidence of carbon disulfide. There was less benzene, toluene, and alcohol than expected from traffic gas. The listed paraffins,

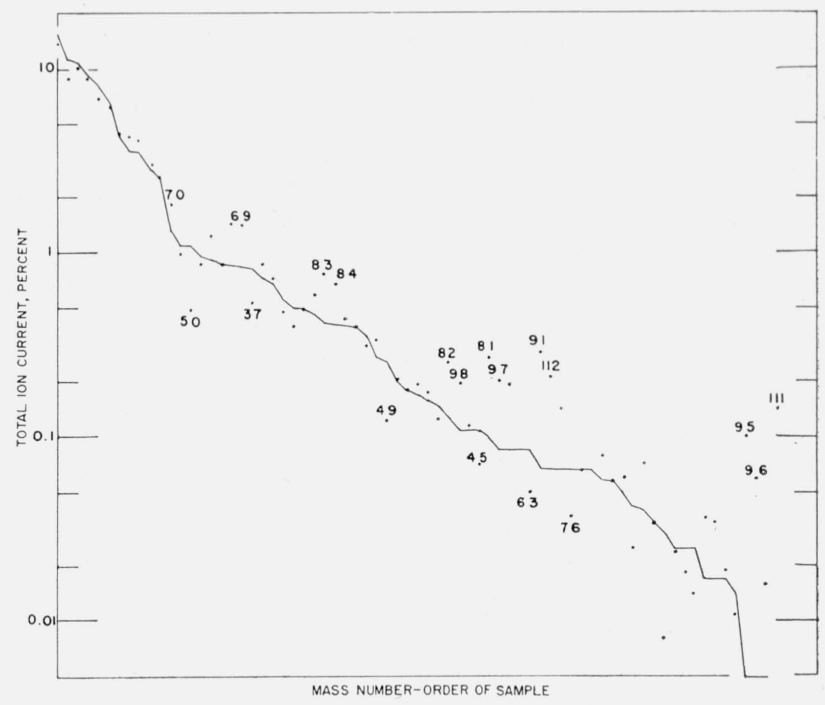

Figure 11. Total contribution of identified substances to the spectrum of Louisville sample G1-L.

—_, Sample; .........., accounted for.

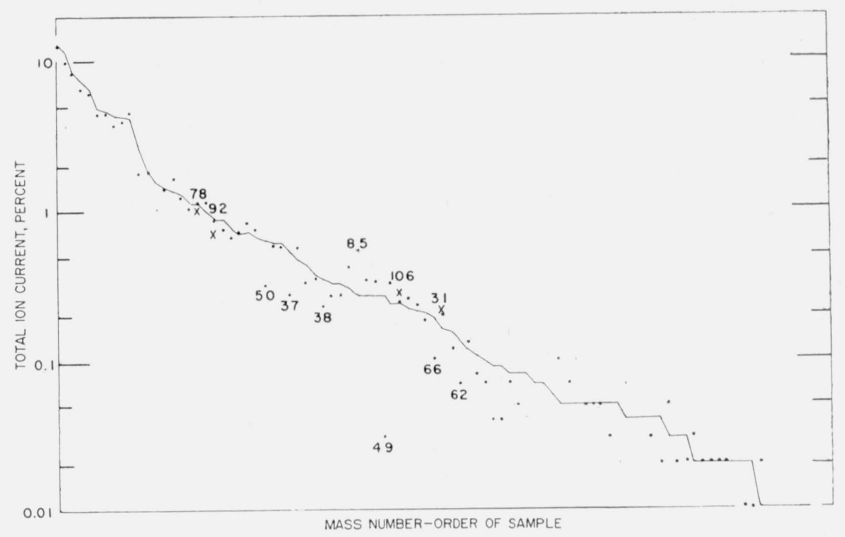

FIgURE 12. Total contribution of identified substances to the spectrum of Louisville sample G2-L.

Sample; ........., accounted for; $\times$, accounted for by NTG only.

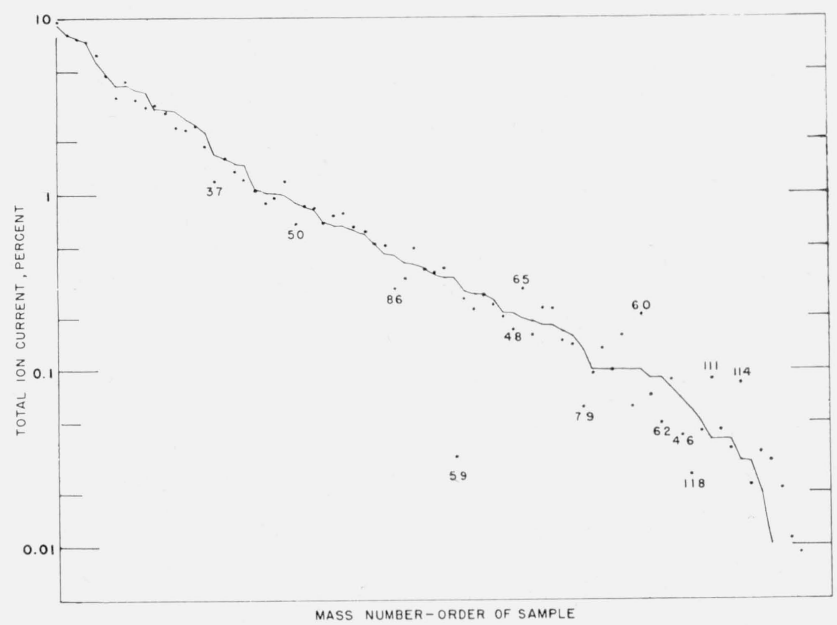

Figure 13. Total contribution of identified substances to the spectrum of Louisville sample G3.

spectrum of Louisville sample Gs. 


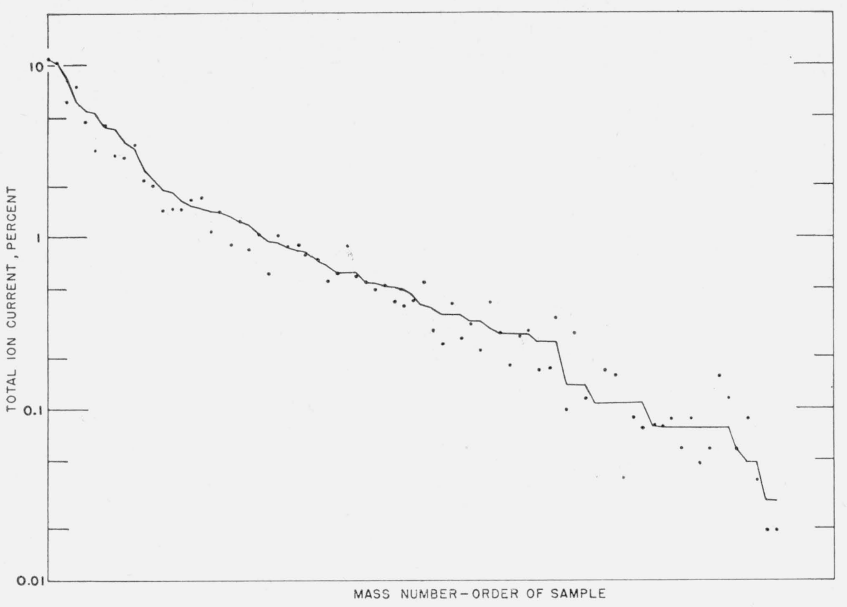

Figure 14. Total contribution of identified substances to the spectrum of Louisville sample G5.

-, Sample; ........., accounted for.

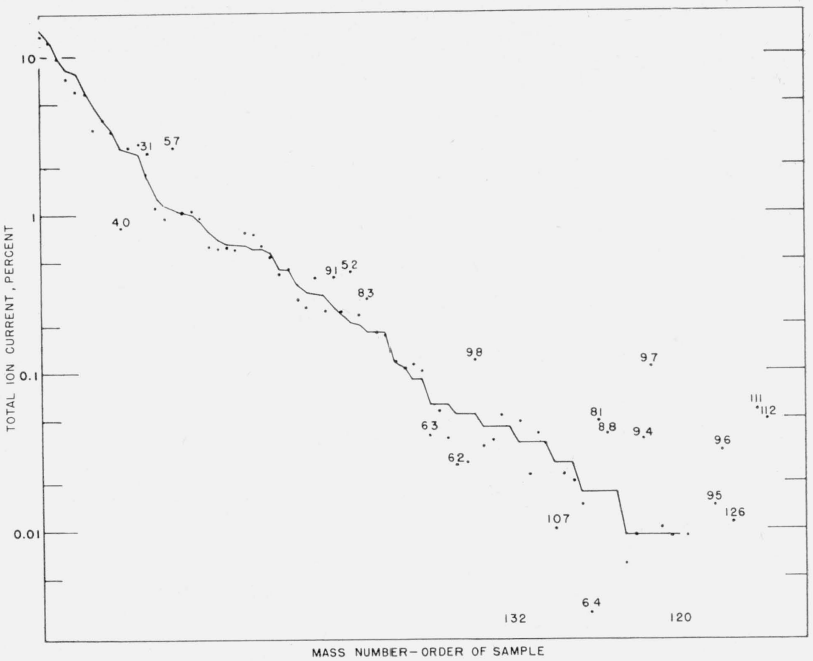

Figure 15. Total contribution of identified substances to the spectrum of Louisville sample G6.

TABLE 8. Interpretation of condensed pollutants from Louisville

(Corrected for diflurodichloromethane)

\begin{tabular}{|c|c|c|c|c|c|c|c|c|}
\hline \multirow{2}{*}{ Sample } & \multicolumn{8}{|c|}{ Mole fraction x100 } \\
\hline & D-6 & $\mathrm{ST}-1$ & $\mathrm{X}-1$ & $\mathrm{G}-1$ & $\mathrm{G}-2$ & $\mathrm{G}-3$ & $\mathrm{G}-5$ & $\mathrm{G}-6$ \\
\hline \multicolumn{9}{|l|}{ Traffic gas: } \\
\hline NTG & 30 & 75 & 16 & 48 & 75 & 65 & 50 & \\
\hline $\begin{array}{l}\text { Ref } \\
\text { Gasoline vapor a }\end{array}$ & & - n-non & 50 & 34 & 10 & 22 & 20 & 53 \\
\hline $\begin{array}{l}\text { Gasoline vapor a } \\
\text { Paraffin hydrocarbons: b }\end{array}$ & 50 & -........ & -n. & -non & -non & 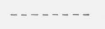 & $-\cdots$ & 31 \\
\hline Normal butane....... & & & 3.80 & & & & & \\
\hline Isobutane ............ & $\ldots+\cdots$ & - & & - non & - n-n & $\ldots \ldots$ & - n-n & 2.3 \\
\hline Normal pentane & - n-n & - non & 0.12 & $\ldots$ & $\ldots$ & - n- & - & 1. 2 \\
\hline $\begin{array}{l}\text { Isohexane.................................. } \\
\text { Olefins: b }\end{array}$ & -........ & 1. 2 & & & & & - & 1. 3 \\
\hline $\begin{array}{l}\text { Olefins: b } \\
\text { cis-2-Pentene. }\end{array}$ & $\ldots$ & 1.67 & \multicolumn{4}{|c|}{ Olefins: b } & & 1.1 \\
\hline 1-Hexene & - n-n & 1. 21 & - & - & - n & - n-n & - n-n & \\
\hline \\
\hline $\begin{array}{l}\text { Other aliphatic hydrocarbons: } \\
\text { A cetylene }{ }^{\circ}\end{array}$ & & & & & & & & \\
\hline 3-Hexyne & 10.01 & 0.61 & 10.70 & 15.4 & 11.0 & 2.1 & 0.6 & $\begin{array}{l}3.1 \\
0.64\end{array}$ \\
\hline 1,3-Butadiene $\mathrm{b}$ & 0.74 & 0.01 & 1.76 & 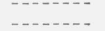 & - & - n & - n & $\begin{array}{r}0.64 \\
.17\end{array}$ \\
\hline Vinyl acetylene..... & .66 & - & & & & - n & - & \\
\hline \multicolumn{9}{|l|}{ Benzene homologs: ० } \\
\hline $\begin{array}{l}\text { Benzene } \\
\text { Toluene }\end{array}$ & .23 & 1. 32 & 3.02 & 1. 2 & 1. 8 & 0.66 & 1. 23 & .31 \\
\hline $\begin{array}{l}\text { Toluene } \\
\text { X vlene and ethyl benzene... }\end{array}$ & .17 & 2.95 & 0.55 & 0.03 & 1. 6 & .66 & 1. 38 & .02 \\
\hline $\begin{array}{l}\mathrm{X} \text { ylene and ethyl benzene. } \\
\text { A bove } \mathrm{C}_{8} \mathrm{H}_{10}\end{array}$ & & 0.67 & .73 & 12 & 0.9 & .17 & 0.43 & -n- \\
\hline $\begin{array}{l}\mathrm{A} \text { hove } \mathrm{C}_{8} \mathrm{H}_{10} \\
\mathrm{C}_{8} \mathrm{H}_{12}\end{array}$ & - n & .97 & .06 & .12 & .2 & .13 & .25 & $-\cdots+-$ \\
\hline $\mathrm{A}$ bove $\mathrm{C}_{9} \mathrm{H}_{12} \ldots$ & n-n & - n & .00 & & -2 & - n & - n & - n \\
\hline $\mathrm{C}_{11} \mathrm{H}_{16}$ & - n & - n & .45 & - n-n & - & - & - & (n-n \\
\hline \multicolumn{9}{|l|}{ Other hydrocarbons: } \\
\hline 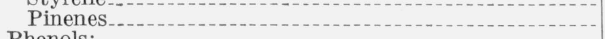 & - non & .78 & .02 & - n-n & 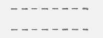 & - & - & - non \\
\hline \multicolumn{9}{|l|}{$\begin{array}{l}\text { Pinenes } \\
\text { Phenols: }\end{array}$} \\
\hline Phenol..... & $\ldots$ & .66 & .11 & - n & & & 4. 84 & .02 \\
\hline \multicolumn{7}{|l|}{ Chlorine derivatives: } & 9.40 & .02 \\
\hline Methyl chloride... & - n- & 0.76 & - & & & & & 1. 2 \\
\hline Dichloromethane & non & .42 & $-\ldots+n$ & - n & (n) & & 3. 94 & \\
\hline Chloroform & -....... & 1. 23 & - n-n & - - n- & - n- & 1. 92 & & \\
\hline $\begin{array}{l}\text { Carbon tetrachloride } \\
\text { Dichloroethane }\end{array}$ & -.......- & & 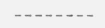 & .2 & 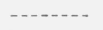 & 11.10 & 0.19 & 0.17 \\
\hline $\begin{array}{l}\text { Dichloroethane } \\
\text { Dichloropropane }\end{array}$ & - n & $\begin{array}{r}0.51 \\
.13\end{array}$ & 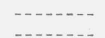 & .2 & - n & n & $-1-1-1$ & $\begin{array}{l}.51 \\
.13\end{array}$ \\
\hline Vinyl chloride & .25 & 10 & 8.51 & .09 & - n & - n-n & - & .13 \\
\hline Dichloroethylene & .29 & .14 & - n- & .2 & $-\cdots$ & $\cdots+\cdots$ & - n- & -1 \\
\hline $\begin{array}{l}\text { Tetrachloroethylene } \\
\text { Chloroprene }\end{array}$ & 3.71 & $-1-1-1$ & 0.06 & $-\cdots+10$ & 1.1 & $-1-1-1$ & 11.4 & .07 \\
\hline Difluorodichloromethane $\mathrm{d}$ & -....- & -non- & ........ & 4.06 & 20.0 & 2.25 & 22.4 & 10.9 \\
\hline $\begin{array}{l}\text { Fluorotrichloromethane } \\
\text { A crvlonitrile }\end{array}$ & 0.16 & .03 & 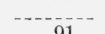 & -.--- & -...- & 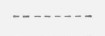 & -.......- & \\
\hline $\begin{array}{l}\text { Acrylonitrile } \\
\text { Ethyl alcohol c }\end{array}$ & $\begin{array}{l}0.16 \\
2.43\end{array}$ & 2.94 & $\begin{array}{r}.91 \\
2.24\end{array}$ & 0.24 & 0.44 & 0.51 & 0.54 & $\begin{array}{r}0.21 \\
.45\end{array}$ \\
\hline Tertiary butyl alcohol & -2.10 & $-2.0 x^{--.--~}$ & 0.14 & - & - & - & - & $\ldots+10$ \\
\hline Carbon disulfide & (n-...- & 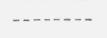 & .13 & 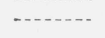 & (nton & non & - n-n & .05 \\
\hline Approximate total pollutant in atmosphere, ppm i...... & - n-..-- & -........ & ......... & .31 & .73 & .47 & 1. 0 & .18 \\
\hline
\end{tabular}

a In addition to gasoline represented by patterns of NTG and Ref.

d Laboratory contamination, not included in computed percentages.
e Acetylene from this sample lost in pretreatment of sample.

b In addition to any of compound represented in patterns of NTG, Ref, and average gasoline.

v Total of compound in sample.
Tome

e Acetylene from this sample lost in pretreatment of sample. 
normal butane and 2-methyl-pentane, were more likely a portion of the gasoline vapor than relatively pure materials from other sources. Their appearance in the accounting probably results from the fact that the pattern of Los Angeles gasoline was derived from completely vaporized fuels of somewhat different general composition. Vapors from stored gasoline must contain a higher fraction of the lower-boiling constituents, and pentane and hexane are underestimated when the regular gasoline pattern is used. There is some evidence of additional olefins, accounted for as isobutene and 1-hexene. They may have been a part of the gasoline vapor, but they may also have come from the same sources that provided the olefins in sample $\mathrm{S} T-1$ that could not be attributed to gasoline. Of the over-accounted-for peaks in this sample, (83), (98), (97), (111), (112), and (126) are evidence of the cycloparaffins in the Los Angeles gasoline pattern; and (81), (94), (95), and (96) are also accounted for entirely by the patterns of gasoline and Ref used. The spectrum actually obtained showed a large quantity of dichlorodifluoromethane which was probably introduced in the laboratory and was, therefore, taken out of the spectrum in advance of the accounting represented by table 8 and figure 15. The Freon was based on the total (87), part of which must have come from something else, for there was not enough (31) and (88) to complete the pattern.

\section{Pasadena Sample S-23}

Among the many old spectra of samples from Southern California, one was of special interest because it was taken during a period of what appeared to be, from the vague description available, one of severe smog; but from a formula based on ratios of certain peaks (see fig. 4), the percent oxidized was only 49.6. Even if the concentration of pollutant was unusually high, a relatively slight effect would have been anticipated from the extent of its oxidation.

The problem was attacked by taking out from the spectrum the pattern of an equal mixture of Ref and NTG, followed by the separation of individual compounds. It was soon evident that the peaks relatively high in N'TG were being "over-accounted for." In effect, the procedure from then on was one of trial and error that resulted in the interpretation shown in table 9 and represented by figure 16 . Table 9 indicates relative concentration only in terms of the percent of total ion current occurring at the principal identifying peak. From this it appears that the sample consisted of traffic gas about 90 percent oxidized to Ref, some aromatic hydrocarbons heavier than benzene, a complex group of cycloparaffins in much greater proportion than is usual even in Southern California, and a number of substances too varied and in too small quantity for identification. Although the cycloparaffins are represented in the table by a half dozen compounds that have a combined spectrum substantially like that of the otherwise unaccounted for residue, it is not to be supposed that they are the only cycloparaffins present. Residues of (125) and (126) probably represent cycloparaffins that could not be fitted by known
TABLE 9. Interpretation of Pasadena smog No. S-23

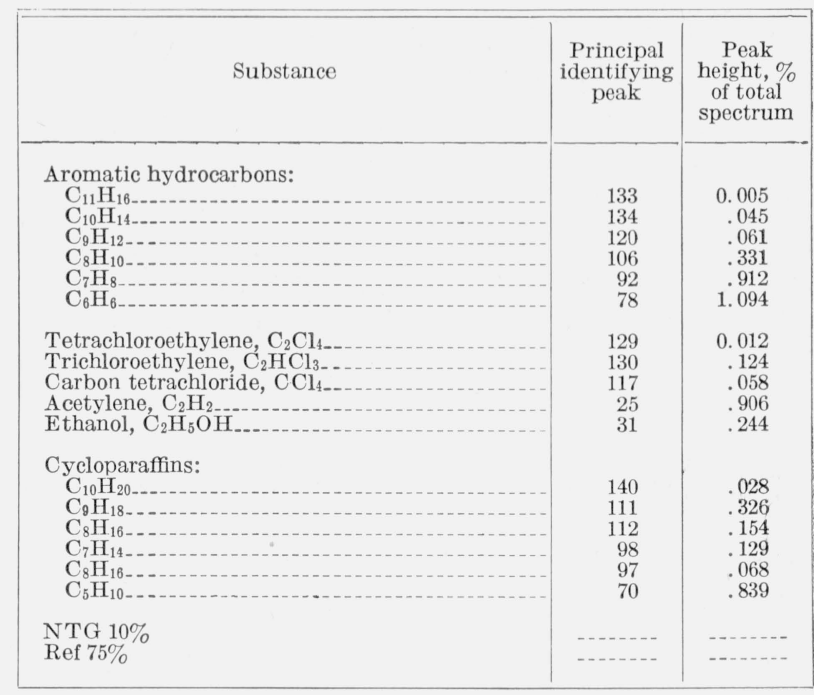

patterns without an excess of lower masses. The catalogs of spectra contain patterns of more than 50 cycloparaffins in the range of molecular weight involved, and a much larger number is possible. The chlorine compounds, alcohol, acetylene, and benzene are present in about their usual proportions in the atmosphere of the region.

It seems probable that the heavy aromatics and the cycloparaffins that distinguish this sample came from a common source that may have been crude oil or a heavy petroleum residue. Because this was a unique sample among many from the same location, it is suggested that a job of paving or road oiling may have been in progress in the neighborhood when the sample was taken. The numerous small unaccounted for residues probably represent slight pollution from varied industrial or domestic sources, including waste disposal.

\section{Detroit Sample No. 5}

A sample taken in Detroit during a period of smog is interpreted so far as seemed practicable in table 10 and figure 17 . The plot, arranged in the order of descending peak heights of the sample, shows excellent agreement with a mixture of 60 percent of NTG and 40 percent of Ref down to a peak height of about 0.1 percent of the total ion current. Beyond that, there are nearly 50 small peaks that are in major part unaccounted for. They indicate a very complicated mixture of pollutants, none of which can be present to the extent of more than a few tenths of 1 percent of the total condensate. In this, they resemble the less numerous unaccounted for residues of Pasadena sample S-23 previously discussed. In the figure the points representing the accounted for portion of these peaks have been labeled, and ions not accounted for at all are indicated by numbers near the bottom of the figure.

The amount of benzene present is a little less than that normally found in traffic gas; toluene is nearly normal, but all the other aromatics much above normal. Alcohol and acetylene are each a little 


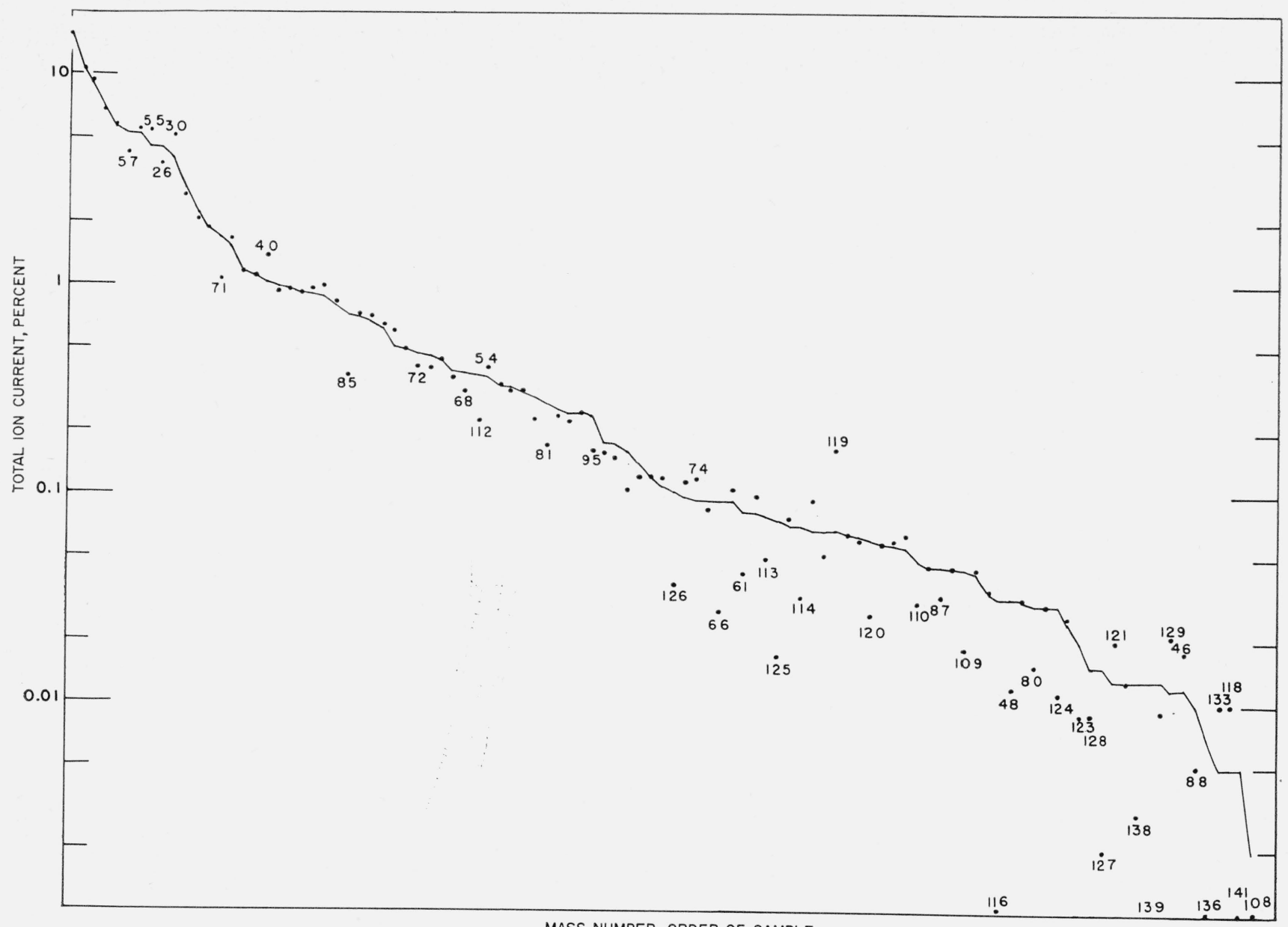

MASS NUMBER-ORDER OF SAMPLE

Figure 16. Total contribution of identified substances to the spectrum of Pasadena sample S-23.

—_ Sample;

Table 10. Composition of Detroit smog No. 5

\begin{tabular}{|c|c|c|}
\hline Substance & $\begin{array}{c}\text { Principal } \\
\text { identifying } \\
\text { peak }\end{array}$ & $\begin{array}{l}\text { Peak } \\
\text { height, \% } \\
\text { of total } \\
\text { spectrum }\end{array}$ \\
\hline $\begin{array}{l}\text { Aromatic hydrocarbons: } \\
\mathrm{C}_{12} \mathrm{H}_{18} \\
\mathrm{C}_{11} \mathrm{H}_{16} \\
\mathrm{C}_{10} \mathrm{H}_{14} \\
\mathrm{C}_{9} \mathrm{H}_{12} \\
\mathrm{C}_{8} \mathrm{H}_{10} \\
\mathrm{C}_{7} \mathrm{H}_{8} \\
\mathrm{C}_{6} \mathrm{H}_{6}\end{array}$ & $\begin{array}{r}147 \\
148 \\
134 \\
120 \\
106 \\
92 \\
78\end{array}$ & $\begin{array}{r}0.021 \\
.009 \\
.058 \\
.024 \\
.437 \\
.499 \\
.629\end{array}$ \\
\hline $\begin{array}{l}\text { Carbon tetrachloride, } \mathrm{CCl}_{4} \\
\text { Ethanol, } \mathrm{C}_{2} \mathrm{H}_{5} \mathrm{OH} \\
\text { Acetylene, } \mathrm{C}_{2} \mathrm{H}_{2}\end{array}$ & $\begin{array}{r}117 \\
31 \\
25\end{array}$ & $\begin{array}{r}.052 \\
1.107 \\
0.647\end{array}$ \\
\hline - & - n-1 & - n \\
\hline
\end{tabular}

less than would be expected for traffic gas. Butadiene appears from (53) and (54) to be about normal for traffic gas, but compounds with six or more carbon atoms and with two double or one triple bond appear in unusual quantity and are indicated by underscored (81), (82), (95), (96), (109), (123), (124), (137), and (138). Identifying connections have not been established between the many small peaks of high mass and their fragments have not been identified among the traffic gases. It is hence impossible to say with certainty what they represent. A reasonable guess can be made at some of them, however, on the ground that some compounds are more commonly used or more volatile than others. For the first reason, (58) is more likely to represent acetone or butane than acetaldehyde, and for both reasons, (116) is more probably from an ester than from an acid or alcohol. Butyl acetate, of parent mass (116), is a widely used solvent in plastic and lacquer industries. As in Louisville, peak (111), which seems always to be the most prominent peak of the cycloparaffins when heights are plotted logarithmically, is more than accounted for by traffic gas alone.

\section{Cincinnati Samples}

Two samples taken in Cincinnati during a period of high barometric pressure, were found to be unique among urban air samples in that they consisted basically of halogen compounds instead of hydrocarbons. One sample is represented by table 11 and figure 18. Hardly more than trace amounts of cresol and phenol were recognized, and no more than the normal amounts of the individually determinable 


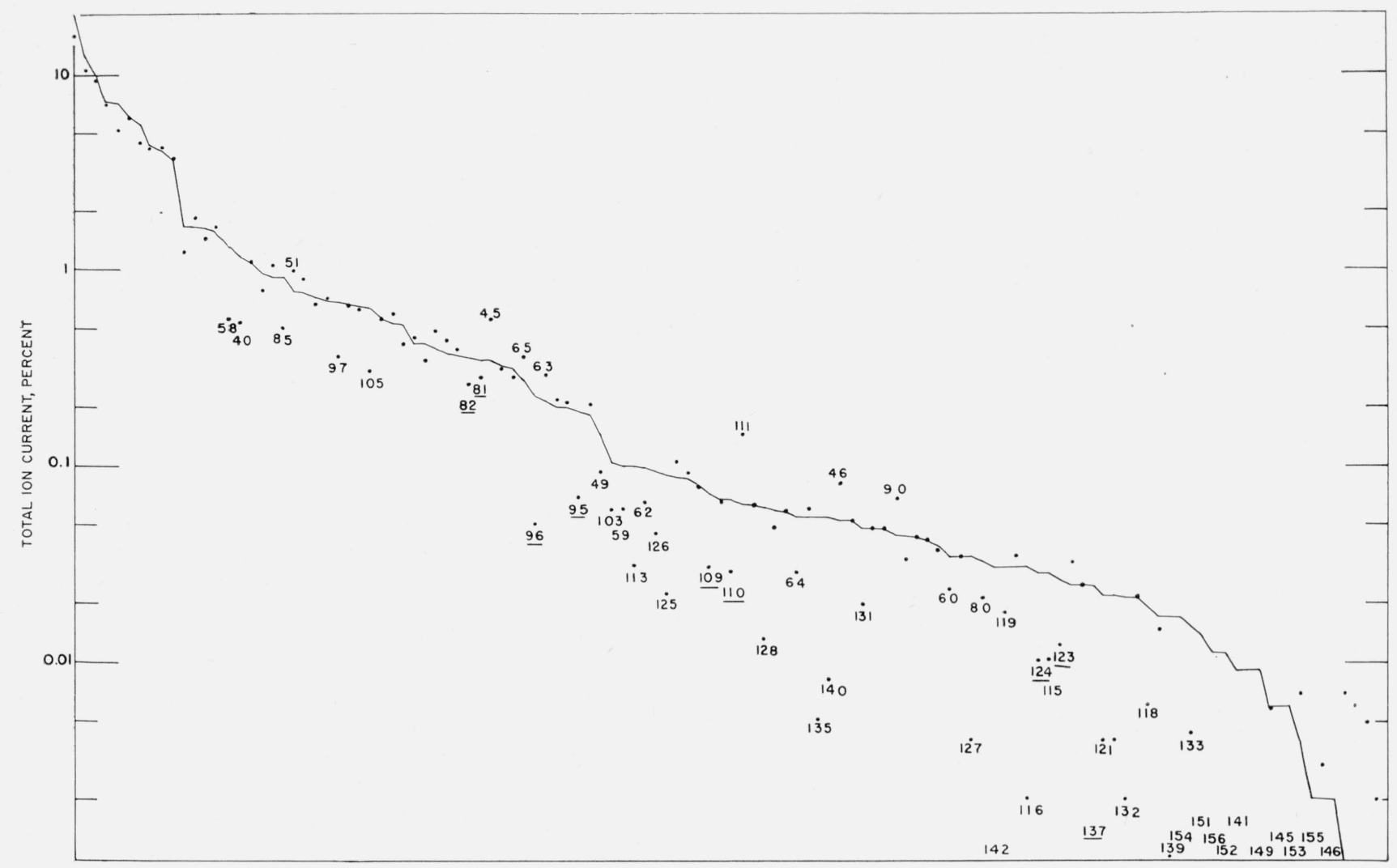

MASS NUMBER-ORDER OF SAMPLE

Figure 17. Total contribution of identified substances to the spectrum of Detroit sample, Smog No. 5.

$\longrightarrow$, Sample; .

Table 11. Composition of Cincinnati smog No. 1

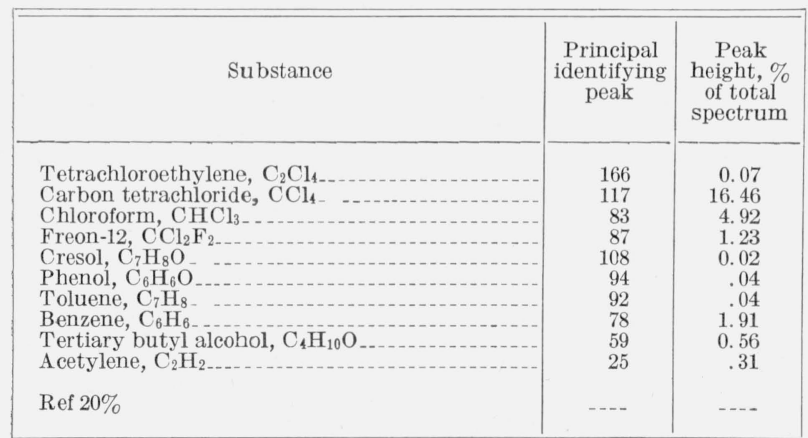

constituents of traffic gas, aromatics, acetylene, and alcohol. As in Detroit, there were numerous but very small unidentified peaks that indicated slight and extremely varied industrial pollution not closely enough related to suggest a common source.

In addition to the difluorodichloromethane believed to have been introduced at the time of analysis, the samples contained carbon tetrachloride, chloroform, tetrachloroethylene, and fluorotrichloromethane. The source of the halogen compounds and its relation to the sampling point is unknown, but it is incredible that halogen derivatives in such quantity can be widespread in the city. A point of general interest is that the portions of the sample attributed to traffic gas were of the approximate composition of

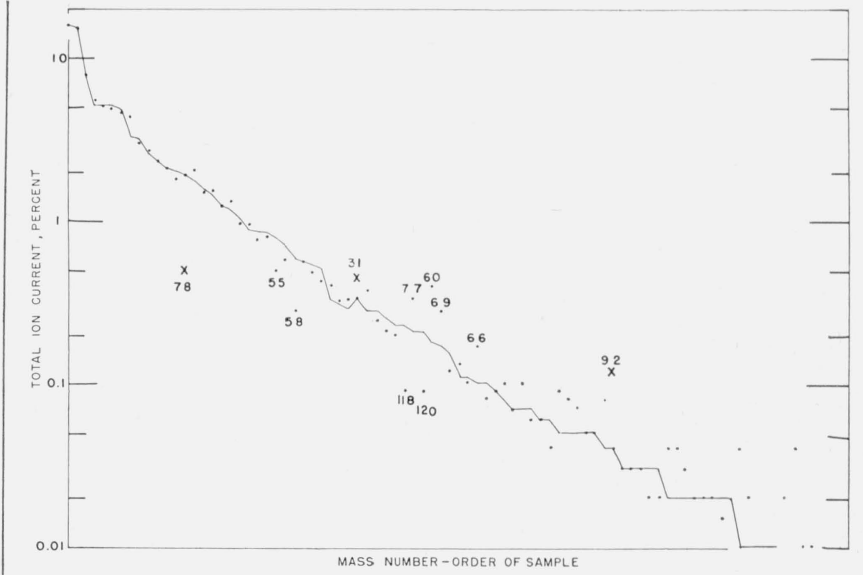

FIgure 18. Total contribution of identified substances to the spectrum of Cincinnati Smog No. 1.

, Sample; .........., accounted for; $\times$, accounted for by traffic gas.

Ref in one sample and at least half Ref in the other. As in Louisville and Detroit, it was evident that the traffic gases had a smaller cycloparaffin content than the traffic gases of Los Angeles and Washington.

\section{Summary and Conclusions}

The composition of the condensate, at liquid oxygen temperature, from any urban atmosphere is too complex for resolution into its individual components; but by considering pollutants from each of 
various sources as substantially constant in composition, it is possible to identify many of the sources and to determine approximately how much each has contributed to the total. This method of study has been applied to condensates from seven cities: Los Angeles, Pasadena, and Wilmington, Calif.; Detroit, Washington, Louisville, and Cincinnati.

The samples from the California cities were numerous and enough alike to be treated, for the purpose of this paper, together. When minor variations have been allowed for, substantially all the samples fall readily into a series of mixtures of regularly changing composition that could be regarded either as blends in different proportions of two basic and nearly uniform mixtures, or as various stages in the transformation of one basic mixture by chemical reactions into another. At one end of the range of composition found in Southern California is a sample taken from a highway tunnel in which it is probable that the pollutant was nearly all from moving automobiles, and at the other end are samples, very much alike, taken at different places during periods of severe smog. If we assume that mixtures of the second type are derived from the first by chemical reactions, it is evident that they are not end products of those reactions, but are the result of an approximately steady state that is approached while the initial substances are regularly poured into a steadily reacting mixture. As a matter of convenience the first stage is referred to as "normal" and the second as "oxidized" traffic gas without implying that these terms tell the whole story. The term "traffic gas" is intended to include engine exhaust gases and the amount of gasoline vaporized in the ordinary handling and use of the fuel.

Condensates from the atmospheres of eastern cities reveal basic pollution, very much like that of southern California, in which variations in the proportions between normal and oxidized traffic gas are clearly discernible. With these traffic gases, which are of substantially constant but virtually unknown chemical composition, a variety of other pollutants occur in relatively small amount. These minor pollutants usually come from local industrial sources. Typical mass-spectral patterns have been selected for the initial and final stages of traffic gas, and when these are taken out of the spectra of condensates under study, the principal pollutants not attributable to automobile traffic are much more easily recognized and determined.

From the studies so far made by this method the following conclusions may be drawn:

1. The pollutants in the air of Washington, D. C., which has almost no chemical industry and in the summer no obvious source of appreciable pollution except traffic gases, resemble the pollutants of Los Angeles very closely. However, the traffic gases are seldom or never in an advanced state of oxidation.

2. As a corollary, we may conclude that industrial pollution in the Los Angeles area is minor or that it is of a character, a mixture of fuel vapors and products of combustion, not readily distinguishable from traffic gas.
3. A group of mass peaks, believed to represent cycloparaffin compounds, is much more prominent in California and Washington traffic gases than in those of Louisville, Detroit, and Cincinnati. This is attributed to the derivation of the motor fuels on the coasts and in the interior from petroleums of different types. With this exception, no general distinction has appeared between traffic gases in various places.

4. Some compounds that occur in all traffic gases have identifying peaks that are relatively free of interference by other compounds ordinarily encountered. They include benzene and toluene as individual compounds, and heavier aromatic hydrocarbons as groups of the same molecular weight, acetylene, and ethyl alcohol. They are determined and taken out of the spectrum of a sample as individual compounds, not as part of traffic gas. Concentrations much greater than normal for traffic gases are noticeable and are attributed to other sources.

5 . In contrast to the uniformity of samples from southern California, samples from Louisville have shown large variations that cannot be attributed to traffic gas. Most of the chemical materials responsible for the larger variations could be identified. Some could be identified only partly or not at all; but essentially the same pattern, repeated in several samples, indicated pollution from a common source which it should be possible to locate by further study.

6. Repeated joint occurrences of the same polutants in samples from Louisville indicate that they originate in the same plant or nearly adjacent plants.

From the analytical data alone, the following grouping appears to be probable:

a. A source of gasoline vapor in large quantity.

b. A source or neighboring sources of acetylene and vinyl chloride.

c. A source or neighboring sources of butadiene, acrylonitrile, chloroprene, vinyl acetylene, and dichloreoethylene.

d. A source of benzene.

e. A source of cresol, phenol, and styrene.

f. A source of pinene.

g. A source or sources of ethyl alcohol.

h. A source of aliphatic chlorine derivatives in considerable variety.

i. A source of olefins in variety.

j. A source of carbon tetrachloride.

k. A source of ion (59) tentatively attributed to tertiary butyl alcohol.

1. A source of ions (49) and (50) not certainly identified with any compound.

\section{References}

[1] Martin Shepherd, Method for identifying and estimating gases and vapors in air pollution, Air Pollution, Proc. 1st U. S. Tech. Conf. on Air Pollution, p. 228 (1952).

[2] Martin Shepherd, S. M. Rock, Royce Howard, and John Stormes, Isolation, identification, and estimation of gaseous pollutants in air, Anal. Chem. 23, 1431 (1951).

[3] E. R. Weaver and Shirley Gunther, Condensible impurities in the air of Los Angeles and vicinity, Proc. 3d Natl. Air Symposium, Pasadena, p. 86 (1955).

Washington, May 20, 1957. 